\section{Wasp Venom Immunotherapy in a Patient With Immune-Mediated Inflammatory Central Nervous System Disease: Is it Safe?}

Nittner-Marszalska $\mathrm{M}^{1}$, Kowal $\mathrm{A}^{2}$, Szewczyk $\mathrm{P}^{3}$, Guranski $\mathrm{K}^{4}$, Ejma $\mathrm{M}^{4}$

${ }^{1}$ Department of Internal Diseases and Allergology, Wroclaw Medical University, Wroclaw, Poland

${ }^{2}$ Department of Pulmonology, Wroclaw Medical University, Wroclaw, Poland

${ }^{3}$ Department of Radiology, Wroclaw Medical University, Wroclaw, Poland

${ }^{4}$ Department of Neurology, Wroclaw Medical University, Wroclaw, Poland

J Investig Allergol Clin Immunol 2017; Vol. 27(2): 127-129 doi: 10.18176/jiaci.0126

Key words: Venom immunotherapy. Wasp venom. Autoimmune disorders.

Palabras clave: Inmunoterapia frente a veneno. Veneno de avispa. Trastornos autoinmunológicos.

Venom immunotherapy (VIT) is the only highly effective way of treating patients with hymenoptera venom allergy (HVA). The most serious anaphylactic symptoms of HVA (HVA-SYS IVo) are life-threatening, thus making their occurrence an unconditional recommendation for VIT. Yet, VIT is contraindicated in immune-mediated inflammatory diseases.

We present the case of a 55-year-old woman with autoinflammatory neurological disease (initially diagnosed with relapsing remitting multiple sclerosis) who received VIT following an anaphylactic reaction (SYS-IVo) to wasp sting (Vespula germanica). Allergy tests showed the presence of specific IgE antibodies to wasp venom (intradermal test at $0.001 \mu \mathrm{g} / \mathrm{mL}, 12 \times 12 \mathrm{~mm}$; sIgE class 2 ). The basal serum tryptase concentration was normal. Her past medical history included gastrointestinal reflux, mild gastritis, allergy to ketoprofen and metamizole sodium, and seronegative spondyloarthropathy. At the age of 50, she was diagnosed with remitting-relapsing multiple sclerosis. Her first symptoms of neurological damage were mild facial weakness, mild instability with the eyes closed in the Romberg test, and clumsy movements of the left hand. Magnetic resonance imaging (MRI) was performed twice and revealed multiple hyperintense areas that were considered demyelinating lesions. The cerebrospinal fluid study showed intrathecal production of immunoglobulins (Tibbling-Link IgG index, 1.75 [normal range, 0.2-0.85]). Visual evoked potentials were normal. Lyme disease was excluded. The patient was treated with intravenous methylprednisolone (Solu-Medrol, $1000 \mathrm{mg} / \mathrm{d}$ over 5 days) during 3 exacerbations of the disease. Progression in her disability was measured using the Kurtzke Expanded Disability Status Scale (EDSS). Her initial EDSS was 1.5, which rose to 4.0 after the last exacerbation of the disease.

The patient met the clinical and immunological criteria for VIT. Another reason in support of the decision to administer VIT was the patient's physical disability, which might have hindered attempts to avoid a sting, especially given that she lives in an area with high exposure to stinging insects. The decision to start VIT was made despite the hitherto accepted belief that autoimmunological diseases constitute a contraindication to immunotherapy. At the time the patient qualified for VIT, her condition was stable, with no new active neurological symptoms.

No complications were recorded during the induction phase (ultrarush; Pharmalgen, ALK-Abelló) and a complete 5 -year course of VIT. There were no local or systemic allergic reactions. Neurological symptoms did not intensify, and no new symptoms appeared. The patient did not experience exacerbation of her neurological disease; the EDSS score remained unchanged. The findings in subsequent MRI examinations of the brain were stable, with no new lesions. The MRI revealed no lesions in the temporal lobes or posterior fossa structures and no juxtacortical lesions (Figure, A). However, numerous, small, irregular, hyperintense, and locally confluent lesions were observed in the FLAIR sequence. These were located in the white matter and showed a predilection for the subcortical area of the frontal and
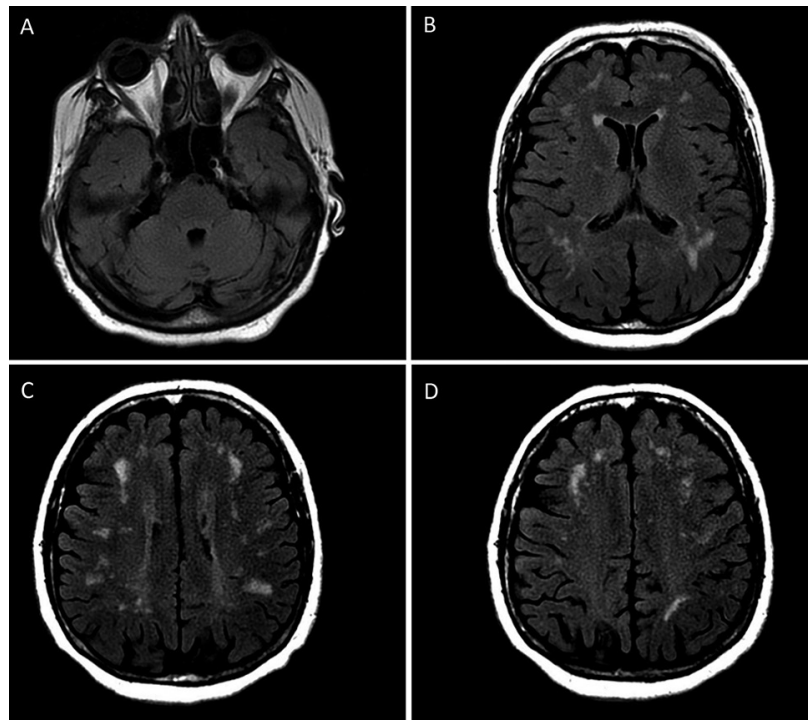

Figure. Magnetic resonance images. 
parietal lobes (Figure, B, C, D); only a few periventricular lesions were visible in the right frontal and parietal lobes (Figure, B). All lesions were irregular and poorly demarcated. Administration of contrast medium did not reveal pathological enhancement of the lesions. The MRI scans of these changes did not meet the McDonald criteria for dissemination in time and space. The image and location of the lesions could suggest an underlying vascular mechanism, especially in the course of vasculitis. The immunological profile of the patient's serum was reassessed. Antinuclear antibodies alone were present; there were no other autoantibodies (anticardiolipin, cANCA, pANCA, SS-A/Ro, Ro-52, SS-B/La, Sm, Sm/RNP, Jo-1, Sci-70, PM-Sci, CENP B, PCNA, dsDNA, histone proteins, anti-P, AMA M2, or dsDNA-NcX IgG). The results of MR angiography of the head were normal. The patient was finally diagnosed with idiopathic primary central nervous system vasculitis. The diagnostic tests excluded the secondary origin of the condition. While VIT did not have a negative effect on the patient's neurological condition, the effectiveness of the therapy cannot be clinically assessed owing to the lack of a field sting. Indirectly, however, it may be endorsed by intradermal test results that are currently positive only at a venom concentration of $1 \mu \mathrm{g} / \mathrm{mL}$.

Co-occurrence of an allergy and an immunemediated inflammatory disease, autoimmune disease, and autoinflammatory disease (AID) is considered an absolute contraindication to allergen immunotherapy (AIT) by some guidelines [1] and a relative contraindication by others [2]. The contraindication results from a hypothetical fear of a negative effect of allergen stimulation on the activity of the inflammatory process and of disturbing $\mathrm{TH}_{1} / \mathrm{TH}_{2}$ balance of peripheral helper $\mathrm{T}$ cells. These concerns are theoretical, because there are no reliable clinical studies or even clinical observations that could confirm them. Actually, such studies would be difficult to carry out, since patients with AID are routinely disqualified from AIT according to existing recommendations.

However reasonable the contraindications in most patients receiving AIT, in the case of life-threatening HVA, the benefits of VIT exceed the risk of an exacerbation of AID, thus explaining why, when justified in patients with AID, VIT can be administered during a stable period of the disease. Of the few reports that describe such procedures, one refers to a patient with HVA and systemic lupus erythematosus who, as in the present case, underwent VIT uneventfully (ie, with no exacerbation of systemic lupus erythematosus) [3].

The lack of a negative interdependence between AIT and AID may also be supported by the fact that there are few reports of manifestations of AIDs during the course of AIT. Reports of vasculitis, scleroderma, Sjögren syndrome, rheumatoid arthritis, and multiple sclerosis during AIT are based on case reports [4-8], whereas the evidence that AIT may reduce the risk of the occurrence of autoimmune diseases is from observational studies. In a registry-based observational study, the incidence of AID was lower in allergic patients treated with AIT than in allergic patients given conventional pharmacotherapy [9]. Similar findings were reported by Bozek et al [10], whose long-term study revealed that the incidence of AID (including systemic vasculitis, multiple sclerosis, rheumatoid arthritis, ulcerative colitis, Crohn disease, Graves disease, scleroderma, and psoriasis) in patients treated with AIT is low and is in fact lower than in allergic patients treated symptomatically [10].

When we decided to administer VIT in the present cases, we were first and foremost concerned for the patient's safety during AIT and feared exacerbation of the neurological condition. However, we also considered the benefits of VIT. Given that neither of these complications occurred, it may be appropriate to recommend VIT in patients with HVA and AID.

\section{Funding}

The authors declare that no funding was received for the present study.

\section{Conflicts of Interest}

The authors declare that they have no conflicts of interest.

\section{References}

1. Pitsios C, Demoly P, Bilo MB, Gerth vanWijk R, Pfaar O, Sturm GJ, Rodriguez Del Rio P, Tsoumani M, Gawlik R, Paraskevopoulos G, Ruëff F, Valovirta E, Papadopoulos NG, Calderon MA. Clinical contraindications to allergen immunotherapy: an EAACI position paper. Allergy. 2015;70(8):897-909.

2. Cox L, Nelson H, Lockey R, Calabria C, Chacko T, Finegold I, Nelson M, Weber R, Bernstein DI, Blessing-Moore J, Khan DA, Lang DM, Nicklas RA, Oppenheimer J, Portnoy JM, Randolph C, Schuller DE, Spector SL, Tilles S, Wallace D. Allergen immunotherapy: a practice parameter third update. J Allergy Clin Immunol. 2011;127:S1-S55.

3. Fiorillo $A$, Fonacier $L$, Diola C. Safety of allergenic immunotherapy in systemic lupus erythematosus. J Allergy Clin Immunol. 2006;117(2 Suppl):S264.

4. Taylor RJ. Hypersensitivity vasculitis occurring in a patient receiving immunotherapy. J Allergy Clin Immunol. 1991;87:889-90.

5. Morfín Maciel BM, Castillo Morfín BM. [Scleroderma related to specific immunotherapy. A report of a case]. Rev Alerg Mex. 2009;56:136-45. Spanish

6. Turkcapar N, Kiniklui G, Sak SD, Duman M. Specific immunotherapy-induced Sjogren's syndrome. Rheumatol Int. 2005;26:182-4

7. Ghoreschi K, Fischer J, Biedermann T. Manifestation of rheumatoid arthritis during subcutaneous allergen-specific immunotherapy with bee venom. J Allergy Clin Immunol. 2012;130:1438-9

8. Nakajima $H$, Ohtsuka $S$, Nishina $T$, Sugino $M$, Kimura $F$, Hanafusa T, Ikemoto T, Shimizu A. Multiple sclerosis after allergen-specific immunotherapy and influenza vaccination. Eur Neurol. 2003;50:248-9. 
9. Linneberg A, Madsen F, Skaaby T. Allergen-specific immunotherapy and risk of autoimmune disease. Curr Opin Allergy Clin Immunol. 2012;12:635-9.

10. Bożek A, Kolodziejczyk K, Bednarski P. The relationship between autoimmunity and specific immunotherapy for allergic diseases. Human Vaccines Immunotherapeutics. 2015;12:2764-8

Manuscript received October 6, 2016; accepted for publication December 7, 2016.

Konstanty Guranski Department of Neurology Wroclaw Medical University, Borowska 213 50-556 Wroclaw, Poland E-mail: kguransk@interia.pl

\section{Pseudomonas aeruginosa Liver Abscess as the First Manifestation of X-Linked Agammaglobulinemia With a Novel Mutation}

Muñoz-Miguelsanz MA ${ }^{1}$, Álvarez Morales T², Martín García JA², Martínez Gallo $\mathrm{M}^{3}$, Santos Pérez $\mathrm{JL}^{2}$

${ }^{1}$ Pediatric Surgery Department, Virgen de las Nieves Children's Hospital, Granada, Spain

${ }^{2}$ Pediatrics Department, Virgen de las Nieves Children's Hospital, Granada, Spain

${ }^{3}$ Immunology Department, Vall d'Hebron Hospital, Barcelona, Spain

J Investig Allergol Clin Immunol 2017; Vol. 27(2): 129-131 doi: $10.18176 /$ jiaci.0129

Key words: X-linked agammaglobulinemia. Primary immunodeficiencies. Liver abscess. Pseudomonas aeruginosa. Children.

Palabras clave: Agammaglobulinemia ligada al X. Inmunodeficiencias primarias. Absceso hepático. Pseudomonas aeruginosa. Niños.

Pyogenic liver abscesses are infrequent in children, occurring in 8-20 per 100000 inpatients [1]. They originate in the intestine or biliary tract or less frequently through hematogenous spreading. The latter is more common in children with underlying diseases, such as primary immunodeficiency, and often with defective phagocytosis and severe cellular or humoral disorders.

Staphylococcus aureus is the most common cause of liver abscesses [2]. Data for other pathogens in children are limited, although $2 \%-6 \%$ of adult liver abscesses are caused by Pseudomonas aeruginosa [3].

We report the case of a pediatric patient with a $P$ aeruginosa liver abscess that was managed medically and diagnosed as $\mathrm{X}$-linked agammaglobulinemia (XLA) with a previously unreported mutation.

A 19-month-old boy with no significant past medical or family history presented with general malaise and high fever (peak, $40^{\circ} \mathrm{C}$ ). On examination, the patient was pale and irritable with mottled skin. Meningeal signs were absent, and the results of the abdominal examination were normal. The leukocyte count was $1.8 \times 10^{3} / \mathrm{mm}^{3}$ (polymorphonuclear, $\left.0.19 \times 10^{3} / \mathrm{mm}^{3}\right)$, and C-reactive protein was $413 \mathrm{mg} / \mathrm{L}$. The patient was started on intravenous cefotaxime, which was switched to meropenem and amikacin after $P$ aeruginosa grew in blood cultures. Urinary and cerebrospinal fluid culture results were normal, as were the chest $\mathrm{x}$-ray and echocardiogram findings. A subsequent abdominal and soft tissue ultrasound showed a liver abscess measuring $24 \times 15 \mathrm{~mm}$ in segment VI of the right lobe and 2 subcutaneous tumors with central necrosis in the right leg and pelvis $(20 \times 10 \mathrm{~mm}$ and $30 \times 10 \mathrm{~mm}$ ). Purulent fluid drained from both abscesses was positive for $P$ aeruginosa. Given the patient's clinical condition and the size of the abscesses, surgery was delayed and medical management was continued. 
Table. Blood Test Results

\begin{tabular}{|c|c|c|c|c|c|}
\hline & Admission & $\begin{array}{c}3 \text { Days } \\
\mathrm{M}+\mathrm{A}\end{array}$ & $\begin{array}{l}11 \text { Days } \\
\mathrm{M}+\mathrm{A}\end{array}$ & $\begin{array}{l}3 \text { Weeks } \\
\mathrm{M}+\mathrm{A}+\mathrm{F}\end{array}$ & $\begin{array}{l}\text { Discharge } \\
2 \text { IV Doses of Ig }\end{array}$ \\
\hline Leukocytes, $\times 10^{3} / \mu \mathrm{L}$ & 1.8 & 27.3 & 8 & 6.4 & 9.1 \\
\hline Neutrophils, $\times 10^{3} / \mu \mathrm{L}$ & 0.19 & & 4.5 & 0.8 & 0.97 \\
\hline Lymphocytes, $\times 10^{3} / \mu \mathrm{L}$ & 0.61 & 4.99 & 2.71 & 4.8 & 7.21 \\
\hline $\mathrm{CRP}, \mathrm{mg} / \mathrm{dL}$ & 41.3 & 8.7 & & 0.9 & 0.2 \\
\hline $\mathrm{ALT}, \mathrm{U} / \mathrm{L}$ & & & 30 & 26 & 29 \\
\hline $\mathrm{AST}, \mathrm{U} / \mathrm{L}$ & & & 19 & 18 & 17 \\
\hline GGT, U/L & & & 48 & 32 & 21 \\
\hline $\mathrm{LDH}, \mathrm{U} / \mathrm{L}$ & & & 317 & 228 & 241 \\
\hline \multicolumn{6}{|l|}{ Humoral Immunity } \\
\hline $\mathrm{C} 3, \mathrm{mg} / \mathrm{dL}$ & & & 146 & & 132 \\
\hline $\mathrm{C} 4, \mathrm{mg} / \mathrm{dL}$ & & & 50 & & 32 \\
\hline $\operatorname{IgA}, \mathrm{mg} / \mathrm{dL}$ & & & 67 & 44 & 33 \\
\hline $\mathrm{IgG}, \mathrm{mg} / \mathrm{dL}$ & & & 544 & 550 & 1310 \\
\hline $\mathrm{IgM}, \mathrm{mg} / \mathrm{dL}$ & & & 12 & 9 & 9 \\
\hline \multicolumn{6}{|l|}{ Lymphocyte Subsets } \\
\hline $\mathrm{NK} / \mu \mathrm{L}(\%)$ & & & $266.8(8.5)$ & $1436.5(22.6)$ & $1320(18.1)$ \\
\hline B lymphocytes/ $\mu \mathrm{L}(\%)$ & & & $6.2(0.23)$ & $6.2(0.1)$ & $19.1(0.3)$ \\
\hline CD3 T lymphocytes/ $\mu \mathrm{L}(\%)$ & & & $2849.7(90.6)$ & $4823.5(76)$ & $5919.3(81)$ \\
\hline CD4 T lymphocytes/ $\mu \mathrm{L}(\%)$ & & & $1982.6(63.1)$ & $3318.2(52.3)$ & $3940.9(54)$ \\
\hline CD8 T lymphocytes/ $\mu \mathrm{L}(\%)$ & & & $572.6(18.2)$ & $1136.2(17.9)$ & $1514.7(20.7)$ \\
\hline Total lymphocytes $/ \mu \mathrm{L}$ & & & 3144.2 & 6349.5 & 7304.3 \\
\hline \multicolumn{6}{|l|}{ Vaccine Antigens } \\
\hline Antimeasles IgG & & & Positive & & \\
\hline Anti-HBsAb & & & Nondetectable & & \\
\hline Antirubella IgG & & & Nondetectable & & \\
\hline Oxidative index test & & & Normal & & \\
\hline
\end{tabular}

Abbreviations: A, amikacin; ALT, alanine aminotransferase; AST, aspartate aminotransferase; CRP, C-reactive protein; F, fluconazole; GGT, $\gamma$-glutamyltransferase; LDH, lactate dehydrogenase; M, meropenem.

Findings from clinical and blood tests improved (Table) and the liver abscess gradually decreased in size. After 3 weeks, Candida parapsilosis was isolated in the blood culture. Therapy was started with liposomal amphotericin B and then switched to intravenous fluconazole once the results of the antifungal susceptibility test were available.

Further investigations included immunological testing. Immunoglobulin levels were as follows: $\mathrm{IgG}, 544 \mathrm{mg} / \mathrm{dL}$; IgA, $67 \mathrm{mg} / \mathrm{dL}$; and IgM, $12 \mathrm{mg} / \mathrm{dL}$. Lymphocyte phenotyping showed marked B lymphopenia $\left(0.1 \% ; 6 / \mathrm{mm}^{3}\right)$. The result of the neutrophil oxidative burst assay was normal. Serological tests for previous vaccines were negative for hepatitis B and rubella and positive for measles.

Given the absence of B cells despite normal immunoglobulin levels, genetic tests were performed to rule out primary immunodeficiency.
The Bruton tyrosine kinase (Btk) gene sequencing revealed a pathogenic hemizygous mutation (c. $1631>2$ TA, exon 16 donor splice site).

Ultrasound confirmed the progressive decrease in the size of the liver abscess until complete disappearance after 1 month of antimicrobial and antifungal treatment. Serial blood cultures were negative for $P$ aeruginosa and Candida species.

Therapy with intravenous immunoglobulins $(0.5 \mathrm{~g} / \mathrm{kg})$ was started, and no new complicated infectious events were detected.

Liver abscesses are very uncommon in children. Classic symptoms such as fever, right upper quadrant pain, and jaundice are more common in adults than in children, who often present nonspecific symptoms, such as gastrointestinal symptoms, respiratory distress, and cutaneous rash. While etiology is varied, P aeruginosa is rare. Moore et al [4] 
reported one of the largest series of liver abscesses in infancy $(\mathrm{n}=124)$. Most cases were pyogenic in origin, although none were caused by $P$ aeruginosa.

No specific guidelines have been drafted for children. However, percutaneous drainage has been recommended in adults in the following cases: abscess size $>5 \mathrm{~cm}$; location on the left side (due to higher risk of rupture); absence of clinical improvement after 72 hours of antibiotic treatment; and increase in size or liver failure [5].

In the case series of Moore et al [4], the initial treatment was conservative. Percutaneous drainage was only performed after no measurable improvement following 24-48 hours of antibiotic treatment. The number of patients treated conservatively was $18 / 124$, with complete resolution and minimal residual lesions at 3 weeks. In the case we report, the abscesses could not be seen on ultrasound after 4 weeks of antibiotic treatment.

A literature search revealed only 2 cases in children presenting with liver abscess caused by $P$ aeruginosa $[6,7]$. In both patients (aged 19 and 36 months), treatment was with intravenous antibiotics and percutaneous drainage. In the first case, surgery was the initial approach. The second case was first managed conservatively. Since the abscess increased in size and new abscesses formed, a percutaneous drain was inserted. However, the patient died.

Severe, persistent or unusual infections in children suggest primary immunodeficiency. Although serum Ig levels were not significantly decreased, the B lymphocyte count was less than $2 \%$, strongly suggesting XLA. The definitive diagnosis of XLA is made based on clinical criteria and the presence of the Btk gene mutation [8]. In the case we present, this mutation affected the second position of the exon 16 donor splice site, leading to nonfunctional incomplete protein production and failure of B lymphocyte maturation.

In XLA, the association between phenotype and genotype is controversial [9]. Mutations in Btk produce mRNA and protein alterations and, subsequently, impairment of B lymphocyte maturation. Using bioinformatics techniques, the potential consequences of mutations can be predicted and classified as severe or less severe. In the present case, the mutation affected splicing, leading to a truncated Btk protein. The consequences of the mutation were therefore considered severe. These mutations are associated with onset before 2 years in invasive infections (sepsis, central nervous system infections, and deep-seated infections) [10]. Less severe mutations have been described in patients with normal Ig levels. In the present case, the clinical course was severe despite the absence of significant hypogammaglobulinemia, which could be characteristic in this mutation. However, in some cases, there is no association between Ig levels at diagnosis and disease severity, suggesting that the severity of the mutation is a better predictor of clinical course. Therefore, therapy with intravenous immunoglobulins was started immediately, and no severe infections were subsequently detected.

We conclude that conservative management based on appropriate antibiotic therapy is a suitable option in liver abscess. Early recognition of conditions associated with primary immunodeficiency is important for diagnosis and successful long-term prognosis.

\section{Funding}

The authors declare that no funding was received for the present study.

\section{Conflicts of Interest}

The authors declare that they have no conflicts of interest.

\section{References}

1. Salahi R, Dehghani SM, Salahi H, Bahador A, Abbasy HR, Salahi F. Liver abscess in children: a 10-year single centre experience. Saudi J Gastroenterol. 2011 May-Jun;17:199-202.

2. Muorah $M$, Hinds $R$, Verma $A$, Yu D, Samyn M, Mieli-Vergani G, Hadzic N. Liver abscesses in children: a single center experience in the developed world. J Pediatr Gastroenterol Nutr. 2006 Feb;42:201-6.

3. Chen WH, Chiu CH, Huang $\mathrm{CH}$, Lin $\mathrm{CH}$, Sun JH, Huang YY, Wang CC. Pyogenic liver abscess caused by Pseudomonas aeruginosa: clinical analysis of 20 cases. Scand J Infect Dis. 2011 Dec;43:877-82.

4. Moore SW, Millar AJ, Cywes S. Conservative initial treatment for liver abscesses in children. Br J Surg. 1994 Jun;81:872-4.

5. Fievet $L$, Michel $J$, Harper $L$, Turquet $A$, Moiton MP, Sauvat F. Management of pediatric liver abscess. Arch Pediatr. 2012 May; 19:497-500.

6. Zaki SA, Khade A. Community-acquired pseudomonas aeruginosa liver abscess with portal vein thrombosis in a child. Int J Crit IIIn Inj Sci. 2014;4:178-80.

7. Lo WT, Wang CC, Hsu ML, Chu ML. Pyogenic liver abscess caused by Pseudomonas aeruginosa in a previously healthy child: report of one case. Acta Paediatr Taiwan. 2000;41:98-100.

8. Bousfiha A, Jeddane L, Al-Herz W, Ailal F, Casanova JL, Chatila T, Conley ME, Cunningham-Rundles C, Etzioni A, Franco JL, Gaspar HB, Holland SM, Klein C, Nonoyama S, Ochs HD, Oksenhendler E, Picard C, Puck JM, Sullivan KE, Tang ML. The 2015 IUIS Phenotypic Classification for Primary Immunodeficiencies. J Clin Immunol. 2015;35:727-38.

9. Endo LW, Giannobile JV, Dobbs AK, Foote JB, Szymanska E, Warnock DG, Cook WJ, Conley ME, Schroeder HW. Membranous glomerulopathy in an adult patient with X-linked agammaglobulinemia receiving intravenous gammaglobulin. J Investig Allergol Clin Immunol. 2011;21(5):405-9.

10. Lee $P P$, Chen TX, Jiang LP, Chan KW, Yang W, Lee BW, Chiang WC, Chen XY, Fok SF, Lee TL, Ho MH, Yang XQ, Lau YL. Clinical characteristics and genotype-phenotype correlation in 62 patients with $\mathrm{X}$-linked agammaglobulinemia. J Clin Immunol. 2010;30:121-31.

Manuscript received July 26, 2016; accepted for publication December 9, 2016.

Juan Luis Santos Pérez Pediatrics Department Virgen de las Nieves Children's Hospital

Avda. Fuerzas Armadas 2 18014 Granada, Spain E-mail jlsantosperez@gmail.com 


\section{Frequency and Course of Eosinophilic Esophagitis During Oral Immunotherapy for Cow's Milk Allergy in a Series of 57 Children}

Gómez Torrijos $E^{1}$, Mendez Díaz $\mathrm{Y}^{1}$, Moreno Lozano $\mathrm{L}^{1}$, Extremera Ortega $\mathrm{AM}^{1}$, Borja Segade $\mathrm{J}^{1}$, Feo Brito $\mathrm{JF}^{1}$, Rodríguez Sánchez $\mathrm{J}^{2}$, García Rodríguez $\mathrm{R}^{1}$

${ }^{I}$ Allergy Department, Hospital General Universitario de Ciudad Real, Ciudad Real, Spain

${ }^{2}$ Gastroenterology Department, Hospital General Universitario de Ciudad Real, Ciudad Real, Spain

J Investig Allergol Clin Immunol 2017; Vol. 27(2): 132-133 doi: $10.18176 /$ jiaci.0130

Key words: Anaphylaxis. Cow's milk allergy. Eosinophilic esophagitis. Dysphagia. Oral immunotherapy.

Palabras clave: Anafilaxia. Alergia a leche de vaca. Esofagitis eosinofílica. Disfagia. Inmunoterapia oral.

Numerous experiences with oral immunotherapy (OIT) for cow's milk (CM) allergy in children have been published in recent decades [1]. The procedure is not risk-free. Immediate reactions are common and while late complications are rare, they are more frequently reported with milk than with other foods [2-4]. Fifty-seven children have undergone OIT for CM allergy in our department and 3 of them were diagnosed with eosinophilic esophagitis (EoE).

The case of patient 1 has been previously described [5]. Patient 2 was referred to our allergy department because he had experienced an episode of mild anaphylaxis at 6 months of age when milk formula was introduced into his diet. Prick tests performed at the time showed positive results to $\mathrm{CM}$ and its proteins ( $\alpha$-lactoalbumin, $\beta$-lactoglobulin, and casein). Specific IgE was positive to $\mathrm{CM}(45.4 \mathrm{kU} / \mathrm{L})$, casein $(50.3 \mathrm{kU} / \mathrm{L})$, and $\beta$-lactoglobulin $(16 \mathrm{kU} / \mathrm{L})$. At the age of 11 years he successfully underwent OIT with $\mathrm{CM}$, and was able to tolerate $250 \mathrm{~mL}$ after a 3-month build-up phase. The following year, the daily doses of CM had to be reduced to $125 \mathrm{~mL}$ because of episodes of bronchospasm with the ingestion of each dose of milk. He also experienced anaphylaxis after eating sheep's cheese. After 3 years of a daily maintenance dose of $125 \mathrm{~mL}$ of $\mathrm{CM}$, the patient began to experience progressive dysphagia to solids and choking. We started treatment with omeprazole $40 \mathrm{mg}$ once daily and maintained regular intake of CM. Two months later we performed the first endoscopy with biopsies and identified 30 eosinophils per high power field (HPF) in the proximal, medial, and distal esophagus. The results met the criteria for EoE established in the 2011 consensus recommendations [4 6]. Four months after the first endoscopy, and having followed a $\mathrm{CM}$-free diet, the patient underwent a second endoscopic biopsy, which revealed no eosinophils in the esophagus. These results confirmed the remission of the EoE. The patient has continued on a CM-free diet for the last 3 years but experienced an episode of anaphylaxis with trace amounts of CM.
Patient 3 is an 8-year-old boy with a history of respiratory infection-induced bronchial hyperresponsiveness and allergy to $\mathrm{CM}$ protein since childhood. He experienced an episode of mild anaphylaxis at 3 months of age when milk formula was introduced into his diet. Prick tests performed at the time showed positive results to CM and its proteins ( $\alpha$-lactoalbumin, $\beta$-lactoglobulin, and casein). Specific IgE was positive to CM (34.5 kU/L), casein $(20.3 \mathrm{kU} / \mathrm{L}), \alpha$-lactoalbumin $(21 \mathrm{kU} / \mathrm{L})$, and $\beta$-lactoglobulin $(16 \mathrm{kU} / \mathrm{L})$. The patient subsequently followed a strict $\mathrm{CM}$ avoidance diet. At the age of 8 years, he successfully underwent OIT for CM allergy, and was able to tolerate $250 \mathrm{~mL}$ of CM after the build-up phase, which lasted 3 months. The following year, daily doses of CM had to be reduced to $125 \mathrm{~mL}$ because the boy experienced episodes of oral allergy syndrome after the ingestion of milk and dairy products. After 3 years of a daily maintenance dose of $125 \mathrm{~mL}$ of $\mathrm{CM}$, he began to experience central chest pain after eating solid foods. He remained asymptomatic for a month after starting a CM-free diet. A new endoscopy with esophageal biopsies by sections (proximal, medial, and distal) identified at least 30 eosinophils/HPF. After 2 years on a CM-free diet, the patient was still asymptomatic and an endoscopy with biopsies showed no eosinophils.

All patients allergic to CM who underwent OIT in our clinic and developed EoE showed unfavorable progress and required a dose reduction of $\mathrm{CM}$ during the first year, despite tolerating $250 \mathrm{~mL}$ at the end of the build-up phase. As is common in patients with severe CM allergy, tolerance was only partially achieved. Failure to tolerate goat's or sheep's cheese or CM is not uncommon in patients after OIT for CM allergy [7] and confirms the high specificity of the desensitization procedure.

Proton pump inhibitors (PPIs) were prescribed after the diagnosis of EoE, as these drugs are considered the first-line treatment for this condition, before diet or topical steroids [8].

In patient 2, the first endoscopy was performed 2 months after PPI treatment was started. Although the patient was already asymptomatic, the histologic findings confirmed the diagnosis of EoE. A second endoscopy performed after 6 months of CM avoidance showed that the EoE was in remission. In this case, similarly to that of patient 1 [5], the period of food avoidance necessary for the resolution of EoE after OIT was longer than the 6 weeks established for diet-based treatments [9]. Besides, the 2 patients lost tolerance of CM within weeks or months of a CM-free diet and experienced anaphylactic episodes after the accidental ingestion of $\mathrm{CM}$.

The prevalence of EoE in our patients (5.2\%) is higher than that previously reported for other foods $(2.7 \%)$ [10]. Although there is a risk of this late complication in patients undergoing food OIT, the potential benefits should be weighed against the risk of immediate, potentially severe reactions due to the accidental ingestion of food. After 5 years, the 3 patients have remained asymptomatic on a CM-free diet.

One limitation of this study is that an esophagoscopy was not performed in any of the the patients before starting OIT and EoE may therefore have been present before the desensitization procedure. The fact that avoidance of CM led to the resolution of the esophageal disease, however, makes it unlikely. 
We have reported on several patients who developed EoE 3 years after OIT for CM allergy and achieved partial tolerance of $\mathrm{CM}$ during the maintenance phase. The favorable clinical and histologic remission after the withdrawal of $\mathrm{CM}$ from the patients' diets confirms that the bovine proteins were responsible for the EoE. Before starting OIT, clinicians should enquire about esophageal dysfunction symptoms. If present, EoE should be ruled out before initiation of therapy. Patients due to undergo OIT should also be warned of the risk of EoE and informed about its symptoms. In brief, the risk-benefit profile of OIT should be carefully evaluated for each patient.

\section{Acknowledgments}

We thank all the nursing staff at the allergy department of our hospital.

\section{Funding}

The authors declare that no funding was received for the present study.

Conflicts of Interest

The authors declare that they have no conflicts of interest.

\section{References}

1. Brozek JL, Terracciano L, Hsu J, Kreis J, Compalati E, Santesso $\mathrm{N}$, Fiocchi A, Schünemann HJ. Oral immunotherapy for IgEmediated cow's milk allergy: a systematic review and metaanalysis. Clin Exp Allergy. 2012;42:363-74.

2. Sánchez-García S, Rodríguez Del Río P, Escudero C, MartínezGómez MJ, Ibáñez MD. Possible eosinophilic esophagitis induced by milk oral immunotherapy. J Allergy Clin Immunol. 2012 Apr; 129(4):1155-7

3. Morais Silva P, Antunes J, Chambel M; Prates S; Leiria Pinto P. Diagnosis of eosinophilic esophagitis in an infant undergoing milk oral immunotherapy -a case report. Eur Ann Allergy Clin Immunol. 2014;46:154-6

4. Ridolo E, De Angelis GL, Dallaglio P. Eosinophilic esophagitis after specific oral tolerance induction for egg protein. Ann Allergy Asthma Immunol. 2011;106;73-4

5. García Rodríguez C, Gómez Torrijos E, De la Roca Pinzón F, Borja Segade J, García Rodríguez R, Feo Brito F, RodríguezSánchez J. Dysphagia in a boy treated with oral immunotherapy for cow's milk allergy. J Investig Allergol Clin Immunol. 2014;24(5):352-4.

6. Liacouras CA, Furuta GT, Hirano I, Atkins D, Attwood SE, Bonis PA, Burks AW, Chehade M, Collins MH, Dellon ES, Dohil R, Falk GW, Gonsalves N, Gupta SK, Katzka DA, Lucendo AJ, Markowitz JE, Noel RJ, Odze RD, Putnam PE, Richter JE, Romero Y, Ruchelli E, Sampson HA, Schoepfer A, Shaheen NJ, Sicherer SH, Spechler S, Spergel JM, Straumann A, Wershil BK, Rothenberg ME, Aceves SS. Eosinophilic esophagitis: updated consensus recommendations for children and adults. J Allergy Clin Immunol. 2011;128(1):3-20.

7. Rodríguez del Río P, Sánchez-García S, Escudero C, PastorVargas C, Sánchez Hernández JJ, Pérez-Rangel I, Ibáñez MD. Pediatr Allergy Immunol. Allergy to goat's and sheep's milk in a population of cow's milk-allergic children treated with oral immunotherapy. Pediatr Allergy Immunol. 2012;23(2):12832.

8. Molina-Infante J, Bredenoord AJ, Cheng E, Dellon ES, Furuta GT, Gupta SK, Hirano I, Katzka DA, Moawad FJ, Rothenberg ME, Schoepfer A, Spechler SJ, Wen T, Straumann A, Lucendo AJ; From the PPI-REE Task Force of the European Society of Eosinophilic Oesophagitis (EUREOS). Proton pump inhibitorresponsive oesophageal eosinophilia: an entity challenging current diagnostic criteria for eosinophilic oesophagitis. Gut. 2016;65(3):524-31

9. Rodriguez Sanchez, Gomez Torrijos, Lopez Biezma, De la Santa Belda, Martín Dávila F, García Rodríguez C, Feo Brito F, Olmedo Camacho J, Reales Figueroa P, Molina-Infante J Efficacy of IgE-targeted vs empiric six-food elimination diets for adult eosinophilic oesophagitis. Allergy. 2014;69(7):93642.

10. Lucendo AJ, Arias A, Tenias JM. Relation between eosinophilic esophagitis and oral immunotherapy for food allergy: a systematic review with meta-analysis. Ann Allergy Asthma Immunol. 2014;113(6):624-629.

Manuscript received August 17, 2016; accepted for publication, December 12, 2016.

Elisa Gómez Torrijos Hospital General de Ciudad Real. Allergy Section c/Obispo R Torija S/N 13005 Ciudad Real, Spain E-mail: egomezt.cr@gmail.com 


\section{Occupational Contact Dermatitis in Spain}

Holguín-Gómez L ${ }^{1}$, Sastre Domínguez $\mathrm{J}^{2}$

${ }^{1}$ Alergología Clínica, Universidad de Antioquia, Colombia and Allergy Division, Fundación Jimenez Díaz

${ }^{2}$ Allergy Division, Fundación Jimenez Díaz, Universidad Autónoma de Madrid, Madrid, Spain

J Investig Allergol Clin Immunol 2017; Vol. 27(2): 134-136 doi: 10.18176/jiaci.0131

Key words: Occupational contact dermatitis. Spain. High-risk occupations.

Palabras clave: Dermatitis de contacto ocupacional. España. Profesiones de alto riesgo.

Occupational contact dermatitis (OCD) is one of the most common work-related illnesses in developed countries, accounting for up to one-third of all occupational diseases. It is an inflammatory skin condition caused by contact with materials found in the workplace. The 3 types of OCD are irritant contact dermatitis, allergic contact dermatitis, and contact urticaria [1].

The annual incidence of OCD is thought to be between 11 and 86 cases per 100000 workers worldwide, and between 5 and 19 cases per 10000 workers per year in Europe. The occupations with the highest risk include hairdressing, baking and other food services, mechanics, painting, construction, footwear manufacturing, health care work, and poultry farm and manual labor [1]. A study conducted by Bordel-Gómez et al [2] in Spain reported a prevalence of $21.3 \%$ for OCD in patients evaluated due to suspected contact dermatitis. The most widely affected workers were metallurgists, construction workers, and hairdressers.

The main risk factor for the development of irritant OCD is a moist environment, frequent trauma, and contact with solvents and detergents [3]. Allergic OCD, on the other hand, requires a T-cell response. In the case of contact urticaria, an IgE mechanism is involved [4].

The aim of the study was to describe the characteristics and sensitization patterns of patients treated at a specialist clinic in Spain following referral for suspected occupational dermatosis.

Information from 118 consecutive patients seen at the occupational allergy clinic of Fundación Jiménez Díaz in Madrid, Spain between October 2013 and August 2016 was evaluated retrospectively by examining the records held at the clinic. The department provides care for a patient population residing in an area of Madrid and surrounding provinces totalling around 8 million inhabitants. Patients were referred mainly by mutual insurance companies.

The evaluation included a physical examination and a complete occupational history, including evaluation of safety data sheets. The criteria proposed by Mathias was used to aid clinicians in assessing for OCD [5].
Patch tests were performed using the T.R.U.E. 36 TEST set and additional Chemotechnique series (e.g., metals, hairdressing products, gums, dyes, epoxy resins) depending on the patients' clinical history. Test results were interpreted using the criteria of the International Contact Dermatitis Research Group.

A slightly higher proportion of women (54\%) than men had OCD. The mean (SD) age of the patients was 38.6 (10.4) years. Of the 76 patients $(64 \%)$ with positive patch tests, $39(51 \%)$ were positive to more than 1 allergen. Atopy was present in $7.6 \%$ of patients. Exposure time before development of skin lesions was less than 1 year in 33\% of patients, 1 to 5 years in $26 \%, 6$ to 10 years in $8 \%$, and more than 10 years in $9 \%$. The exposure time was unknown in $23 \%$ of patients. The hands were the most frequently affected area; $73 \%$ of all patients had OCD of the hands, which was allergic in $51.6 \%$ of cases and irritant in $21.3 \%$. The next most frequently affected areas were the arms and/or forearms $(32.6 \% ; 21.35 \%$ allergic and $11.2 \%$ irritant $)$ and the face and/ or neck $(21.3 \% ; 17.6 \%$ allergic). The chest and/or lower limbs and widespread involvement were present in $6.7 \%$ and $5.6 \%$ of cases, respectively.

The patch test results are summarized in Figure A. The most frequently positive allergens were metals (29.4\%), including nickel, cobalt, copper, vanadium, palladium, gold thiosulfate, and chromium. The reaction was clinically irrelevant in $30 \%$ of cases. The next most frequently positive allergens were rubber additives (black rubber, thiuram mix, carba mix, and colofony) and hairdressing products. Combined, rubber additives and hairdressing products accounted for $14 \%$ of cases. Methylchloroisothiazolinone/methylisothiazolinone (MCI/MI) was positive in $9.8 \%$ of patients and epoxy resins in $8.4 \%$ (Figure A).

In hairdressers, the most common positive allergens were p-phenylenediamine (19.5\%), metals, acrylates, and MCI/MI (14.6\% each). In construction and handling of resins, the 2 major allergens were epoxies and carba mix, which were both positive in $30.8 \%$ of patients. For workers using cleaning products, the most common sensitizers were thiuram, MCI/MI, and nickel $(30 \%, 20 \%$, and $20 \%$, respectively). In mechanics and the automotive industry and other occupations involving the use and/or maintenance of machines, the main allergens were epoxy resin (33.3\%), formaldehyde, quaternium-15, metals, and colophony ( $16.7 \%$ each).

The definitive diagnosis was allergic contact dermatitis in $52.5 \%$ of patients and irritant dermatitis in $22.9 \%$. Other diagnoses were chronic urticaria/angioedema (3.4\% of cases), atopic dermatitis $(1.7 \%)$, and other nonallergic skin diseases $(19.5 \%)$. The occupations with the highest risk were related to hairdressing $(26 \%)$, building and handling of resins $(15 \%)$, cleaning $(10 \%)$, mechanical tasks, use and maintenance of machinery and the automotive industry ( $8 \%$ ), food services and handling (7\%), and health care work and the pharmaceutical industry (5\%) (Figure B).

The European Surveillance System on Contact Allergy (ESSCA) network identified 10617 patients from 11 European countries with a diagnosis of OCD during the years 2002 to 2010 [6]. The occupations associated with the highest risk of OCD were "other personal service workers", where hair 
A

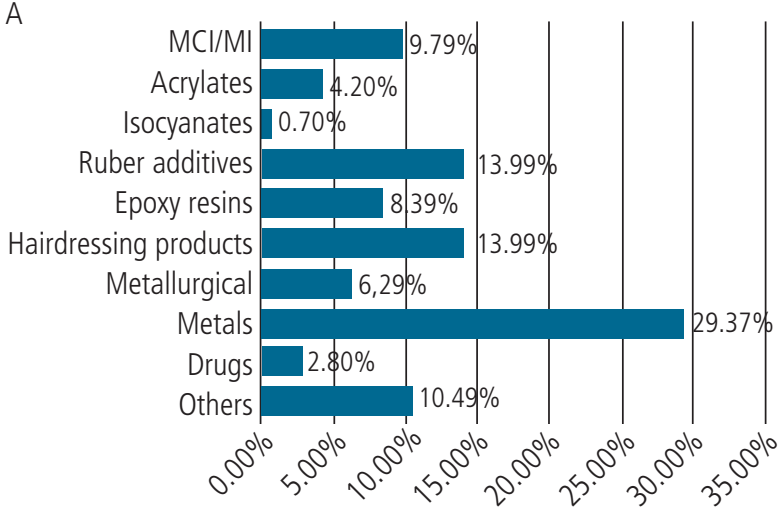

B

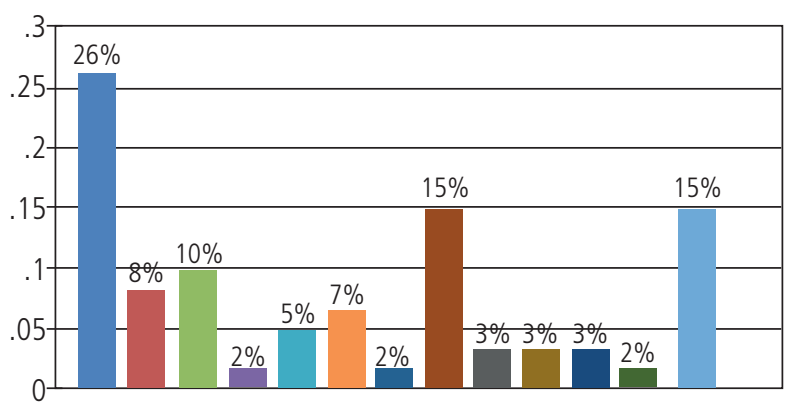

- Hairdressing

- Mechanical tasks, use and maintenance of machinery and the automotive industry

- Cleaning

- Footwear manufacturing

- Healthcare workers and the pharmaceutical industry

- Food services and handling

- Baking

- Building and handling of resins

- Metallurgical

- Painting and varnishing

- Eolic energy industry

- Gardening

- Others

Figure. Sensitization profile (A) and type of activity (B) in allergic occupational contact dermatitis. MCI/MI indicates methylchloroisothiazolinone/ methylisothiazolinone.

and beauty are a major component $(17.4 \%)$ as well as those related to health (2.5\%-17.9\%) and metallurgy/ironworks (up to $12.9 \%)$. The most common allergens were thiuram $(5.35 \%)$, $\mathrm{MCI} / \mathrm{MI}$ (4.09\%), and epoxy resins (3.42\%). These findings coincide with those of Bensefa-Colas et al [7] in France in 2014 and Bauer in Germany in 2015 [8]. Apart from the previously described high-risk populations, our study also detected cleaning as a profession that is particularly vulnerable to OCD, coinciding with reports by Bauer [9] and Mirabilli et al in Spain [10]. We did not find OCD to be as frequent among health care workers as described by the ESSCA network [6]. Additionally, the trend toward a decreased prevalence of OCD in construction workers was confirmed $[7,10]$.
The final diagnosis was allergic contact dermatitis in $53 \%$ of patients and irritant contact dermatitis in $23 \%$, thus contrasting with the 2010 findings of the ESSCA, which reported that irritant OCD was more frequent [8]. This discrepancy may be due to bias in patient referrals in both studies.

\section{Acknowledgements}

Oliver Shaw for editorial assistance.

\section{Funding}

The authors declare that no funding was received for the present study.

\section{Conflicts of Interest}

The authors declare that they have no conflicts of interest.

\section{References}

1. Qin R, Lampel HP. Review of Occupational Contact Dermatitis-Top Allergens, Best Avoidance Measures. Curr Treat Options Allergy. 2015;2:349-64.

2. Bordel-Gómez MT, Miranda-Romero A, CastrodezaSanz J. Epidemiology of contact dermatitis: prevalence of sensitization to different allergens and associated factors. Actas Dermosifiliogr. 2010;101:59-75.

3. Friis UF, Menné T, Schwensen JF, Flyvholm MA, Bonde JPE, Johansen JD. Occupational irritant contact dermatitis diagnosed by analysis of contact irritants and allergens in the work environment. Contact Dermatitis. 2014;71:364370.

4. Amaro C, Goossens A. Immunological occupational contact urticaria and contact dermatitis from proteins: A review. Contact Dermatitis. 2008;58:67-75.

5. Mathias CGT. Contact dermatitis and workers' compensation: criteria for establishing occupational causation and aggravation. J Am Acad Dermatol. 1989;20:842-8.

6. Pesonen $M$, Jolanki $R$, Larese--Filon $F$, Wilkinson $M$, Kręcisz B, Kieć-Świerczyńska M, Bauer A, Mahler V, John SM, Schnuch A, Uter W; ESSCA network. Patch test results of the European baseline series among patients with occupational contact dermatitis across Europe-analyses of the European Surveillance System on Contact Allergy network, 2002-2010. Contact Dermatitis. 2015;72:154-163.

7. Bensefa-Colas L, Telle-Lamberton M, Paris C, Faye S, Stocks SJ, Luc A, Bourrain JL, Crépy MN, Dupas D, Frimat P, Garnier $R$, Lehucher-Michel MP, Pairon JC, Soulat JM, Lasfargues $G$, Choudat D. Occupational allergic contact dermatitis and major allergens in France: Temporal trends for the period 2001-2010. Br J Dermatol. 2014;171:1375-85.

8. Bauer A. Contact dermatitis in the cleaning industry. Curr Opin Allergy Clin Immunol. 2013;13:521-4.

9. Mirabelli MC, Vizcaya D, Martí Margarit A, Antó JM, Arjona L, Barreiro E, Orriols R, Gimenez-Arnau A, Zock JP. Occupational risk factors for hand dermatitis among professional cleaners in Spain. Contact Dermatitis. 2012;66:188-96. 
10. Condé-Salazar L, Guimaraens D, Villegas C, Romero A, Gonzalez M. Occupational allergic contact dermatitis in construction workers. Contact Dermatitis. 1995;33:226-30.

Manuscript received November 25, 2016; accepted for publication, December 15, 2016.

\section{Delayed Allergic Reaction to Terbinafine With a Positive Lymphocyte Transformation Test}

Gonzalez-Cavero L ${ }^{1}$, Dominguez-Ortega $\mathrm{J}^{1,3}$, Gonzalez-Muñoz $\mathrm{M}^{2}$, Mayor-Ibarguren $\mathrm{A}^{4}$, Tomás $\mathrm{M}^{1}$, Fiandor $\mathrm{A}^{1}$, Quirce $\mathrm{S}^{1,3}$ ${ }^{1}$ Department of Allergy, Hospital La Paz Institute for Health Research (IdiPAZ), Madrid, Spain

${ }^{2}$ Department of Immunology, Hospital La Paz, Madrid, Spain

${ }^{3}$ CIBER de Enfermedades Respiratorias, Ciberes, Madrid, Spain ${ }^{4}$ Department of Dermatology. Hospital La Paz, Madrid, Spain

Fundación Jiménez Diaz Servicio de Alergología Av. Reyes católicos 2 28040 Madrid, Spain E-mail: jsastre@fjd.es

J Investig Allergol Clin Immunol 2017; Vol. 27(2): 136-137 doi: 10.18176/jiaci.0133
Key words: Terbinafine. Allergy. Delayed reaction. Lymphocyte transformation test.

Palabras clave: Terbinafina. Alergia. Reacción retardada. Test de transformación linfoblástica.

Terbinafine, a member of the allylamine class of antifungals, is one of the most commonly used drugs for the treatment of dermatophyte infections. Terbinafine exerts its pharmacological effect by inhibiting the early stage of the synthesis of ergosterol, a primary component of the fungal cell membrane; this causes ergosterol deficiency and accumulation of squalene, resulting in cell death [1]. Adverse reactions, most commonly mild gastrointestinal symptoms, are reported by approximately $10 \%$ of patients. Rarely, terbinafine may cause cutaneous adverse effects, such as rash, eczema, or pruritus, with an incidence of $2.7 \%$ [2]. The incidence of serious adverse effects is just $0.04 \%$ [3]. There have also been isolated reports of selective hypersensitivity reactions to this drug, including rare cases of erythema multiforme [3], Stevens-Johnson syndrome or toxic epidermal necrolysis [4,5], and acute generalized exanthematous pustulosis [6].

We present the case of a 34-year-old Bolivian woman with no significant personal history. In February 2016, she was prescribed oral terbinafine (Lamisil, Novartis Pharma) $250 \mathrm{mg} /$ day and topical terbinafine (Lamisil tópico 1\%, Novartis Pharma), 1 topical application over the infected area every 12 hours, for treatment of a Trichophyton rubrum infection affecting the gluteal area. Three days later, she experienced an episode of itchy skin in the area of application. A dermatologist evaluated the patient, recommended discontinuation of terbinafine therapy, and prescribed topical betamethasone and copper sulfate. However, the patient experienced worsening during the next 3 days, with development of progressive, coalescent, punctate, erythematous lesions spreading throughout the buttocks, groin, and thighs, with mild desquamation in some previously affected areas. There was no oral or mucosal involvement, and no pustular or vesicular lesions were observed. Eosinophilia was not present and no other organs or systems were involved. The patient reported no history of adverse reactions to any cosmetics, metal objects, or foods. She recovered completely after a 2 -week course of oral prednisone and went on to complete itraconazole therapy for her fungal infection. 
One month after the episode, a skin prick test with terbinafine $(50 \mathrm{mg} / \mathrm{mL})$ was performed and found to be negative. Patch tests with a standard T.R.U.E. TEST series (SmartPractice Denmark $\mathrm{ApS}$ ) and terbinafine 1\% in petrolatum [7] were also negative. In an attempt to clarify the underlying mechanism, 3 months after the reaction, we performed a lymphocyte transformation test (LTT) with terbinafine. Briefly, proliferation of lymphocytes from the allergic patient was measured as previously described [8]. Fresh peripheral-blood mononuclear cells separated over a density gradient (Histopaque-1077, SigmaAldrich) were incubated for 6 days at $10^{6}$ cells $/ \mathrm{mL}$ in triplicate with terbinafine $(100 \mu \mathrm{g} / \mathrm{mL}-1 \mu \mathrm{g} / \mathrm{mL})$. Phytohemagglutinin $(5 \mu \mathrm{g} / \mathrm{mL})$ was used as a positive control. Proliferation was determined by the addition of $\left[{ }^{3} \mathrm{H}\right]$ thymidine $(0.5 \mu \mathrm{Ci} /$ well $)$ for the final 18 hours of the incubation period. Proliferative responses were calculated as stimulation indices (SI), defined as the ratio between the mean values of counts per minute in cultures with antigen and those obtained without antigen. A positive response, defined as an SI of over 2, was obtained with the drug. LTT with terbinafine in 3 different atopic and nonatopic controls showed no proliferative responses (Figure). As the patient refused to undergo any other in vivo tests, an oral challenge with the culprit drug was not performed.

We have reported on a patient who developed a delayed pruritic, punctate, and erythematous skin eruption after intake of terbinafine, with favorable response to discontinuation of the drug and systemic corticosteroid therapy. The clinical picture was consistent with symmetrical drug-related intertriginous and flexural exanthema (baboon syndrome) induced by terbinafine. The first administration of the drug in the gluteal area could have had some influence on the development of this clinical picture, but, unfortunately, a biopsy was not performed during the acute episode. The implication of terbinafine in the reaction was confirmed by a positive LTT. This diagnostic modality has been used previously to assess delayed allergic reactions $[9,10]$. It offers advantages over patch and intradermal tests, including absolute safety and the assessment of a T-cell response to the drug, especially when performed 3 to 9 months after the onset of the reaction.

To the best of our knowledge, this is the first reported case of hypersensitivity to terbinafine in which this drug was confirmed as the culprit by a positive LTT. The LTT could become a good diagnostic alternative for patients who experience delayed reactions to terbinafine.

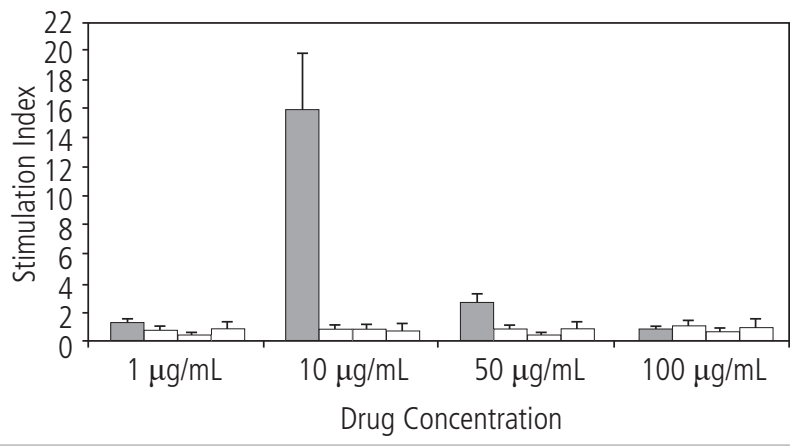

Figure. Lymphocyte transformation test results for different concentrations of terbinafine. Results are expressed as mean stimulation index of triplicate cultures. Error bars show SD. Solid fill and open bars represent the results from the patient and healthy controls $(n=3)$, respectively.

\section{Funding}

The authors declare that no funding was received for the present study.

\section{Conflicts of Interest}

The authors declare that they have no conflicts of interest for this article.

\section{References}

1. Van Duyn Graham L, Elewski B. Recent updates in oral terbinafine: its use in onychomycosis and tinea capitis in the US. Mycoses. 2011;54:e679-85.

2. Ozturk G, Turk BG, Karaca N, Karaarslan IK, Ertekin B, Kazandi A, Kandilog G. Generalized pustular eruption due to terbinafine. Cutan Ocul Toxicol. 2012;31:81-4.

3. Todd P, Halpern S, Munro DD. Oral terbinafine and erythema multiforme. Clin Exp Dermatol. 1995;20:247-8.

4. Terrab Z, El Quazzani T, Zouhair K, El Kabli H, Lakhdar H. Terbinafine-induced Stevens-Johnson syndrome and aggravation of systemic lupus erythematosus. Ann Dermatol Venereol. 2006; 133 (5 Pt 1): 463-6.

5. White SI, Bowen-Jones D. Toxic epidermal necrolysis induced by terbinafine in a patient on long-term anti-epileptics. $\mathrm{Br} J$ Dermatol. 1996;134:188-9.

6. Sidoroff A, Dunant A, Viboud C, Halevy S, Bavinck JN, Naldi L, Mockenhaupt M, Fagot JP, Roujeau JC. Risk factors for acute generalized exanthematous pustulosis (AGEP)-results of a multinational case-control study (EuroSCAR). Br J Dermatol. 2007;157:989-96.

7. Lobera Labairu T, Padial Vilchez MA, Guerrero García MA, Audicana Berasategui MT, García Abujeta JL. Concentraciones de principios activos y excipientes empleados para la realización de pruebas cutáneas. In: Dávila González IJ, Jáuregui Presa I, Olaguibel Rivera JM, Zubeldia Ortuño JM. Tratado de Alergología. 2 Ed. Ergón. Madrid. 2016;1657-98.

8. Pichler WJ, Tilch J. The lymphocyte transformation tests in the diagnosis of drug hypersensitivity. Allergy. 2004;59:809-20.

9. Jurado-Palomo J, Cabañas R, Prior N, Bobolea ID, Fiandor-Román AM, López-Serrano MC, Quirce S, Bellón T. Use of the lymphocyte transformation test in the diagnosis of DRESS syndrome induced by ceftriaxone and piperacillin-tazobactam: two case reports. J Investig Allergol Clin Immunol. 2010;20:433-6.

10. Dominguez-Ortega J, Entrala A, Pola-Bibian B, GonzalezMuñoz M, Fiandor A, Quirce S. Delayed allergic reaction to acenocoumarol with a positive lymphocyte transformation test. J Investig Allergol Clin Immunol. 2016;26:273-4.

Manuscript received October 18, 2016; accepted for publication, December 19, 2016

Lourdes Gonzalez-Cavero Servicio de Alergia

Hospital Universitario La Paz

Paseo de la Castellana, 261

28046 Madrid, Spain

E-mail: lourdesgcavero@gmail.com 


\section{Steps Towards Clarifying the Clinical Relevance of Minor Olive Allergens in Areas With Extremely High Levels of Olive Pollen}

Alcántara $\mathrm{M}^{1}$, Sáenz de San Pedro $\mathrm{B}^{1}$, Cañada $\mathrm{C}^{1}$, Muñoz $\mathrm{MA}^{1}$, Jimeno $\mathrm{L}^{2}$, Villalba $\mathrm{M}^{3}$, de la Torre $\mathrm{F}^{2}$

${ }^{1}$ Allergology Unit of the Complejo Hospitalario de Jaén, Jaén, Spain ${ }^{2}$ ALK-Abelló, SA, Madrid, Spain

${ }^{3}$ Department of Biochemistry and Molecular Biology, Chemical Sciences Faculty, Universidad Complutense de Madrid, Madrid, Spain

J Investig Allergol Clin Immunol 2017; Vol. 27(2): 138-140 doi: $10.18176 /$ jiaci.0134

Key words: Allergic respiratory disease. Allergic sensitization profiles. Component-resolved diagnosis. Olea europaea.

Palabras clave: Diagnóstico por componentes. Enfermedad alérgica respiratoria. Perfiles de sensibilización alérgica. Olea europaea.

Sensitization patterns are highly influenced by allergen pressure, and in areas with sustained high pollen levels, minor allergens can behave as major allergens [1]. Olive pollen is a good example of this behavior. The prevalence of positive IgE results to minor allergens (Ole e 7 and/or Ole e 9) among patients allergic to olive pollen is almost $50 \%$, with Ole e 7 being the primary sensitizer in specific individuals [1]. Furthermore, sensitivity to Ole e 7 has been associated with food anaphylaxis [2], although no cross-reactivity has been described between this allergen and food lipid transfer proteins (LTPs) [3]. In a recent study on the clinical role of olive pollen allergens, the authors hypothesized that Ole e 7 and 9 "seem to be markers of sensitization to panallergens, rather than specific pollen molecules" [4].

The aim of the present study was to determine the influence of allergen pressure on allergic sensitization profiles, the role of minor allergens, and the possible therapeutic implications in patients who are allergic to olive pollen recruited from an area of extreme olive pollen levels.

The study population comprised 100 consecutive patients recruited outside the olive pollination period. All participants had a history of allergic respiratory disease [5-6] by sensitization to olive tree pollen, positive skin prick test (SPT) results (mean wheal diameter, $>3 \mathrm{~mm}$ ) with olive pollen extract, and no previous allergy immunotherapy (AIT). They had all lived in the province of Jaen (Spain) for at least 5 years before their inclusion in the study.

This study was performed with the approval of the Research Ethics Committee of the Province of Jaen, and written informed consent was obtained from all participants.

ImmunoCAP (Thermo Fisher Scientific) was used to measure specific $\operatorname{IgE}(\mathrm{s} \operatorname{IgE})$ reactivity to the following allergens: Ole e 1, 7, and 9; Phl p 1, 5, 7 (polcalcin), and 12 (profilin); Sal k 1; and Cup s 1.

Table. Sensitization Profiles of Study Patients With slgE Negative to Ole e 1, Ole e 7, and Ole e 9

\begin{tabular}{|c|c|c|c|c|c|c|c|c|c|}
\hline Patient & Ole e 1 & Ole e 9 & Ole e 7 & Phl p 1 & Phl p 5 & Phl p 7 & Phl p 12 & Sal k 1 & Cup s 1 \\
\hline $1^{\mathrm{a}}$ & 0.22 & 0 & 0 & 2.67 & 3.11 & 0 & 0 & 0.01 & 0.02 \\
\hline 7 & 0 & 0 & 0 & 0.01 & 0 & 0 & 0 & 0.17 & 0.02 \\
\hline $12^{\mathrm{a}}$ & 0.05 & 0 & 0 & 15.9 & 0 & 0 & 0.01 & 11.3 & 0.01 \\
\hline 13 & 0.02 & 0.01 & 0 & 1.96 & 0 & 0 & 0.01 & 0.01 & 0.02 \\
\hline 16 & 0 & 0 & 0 & 1.35 & 3.73 & 0 & 0 & 0.03 & 0.02 \\
\hline $20^{\mathrm{a}}$ & 0.26 & 0 & 0 & 1.72 & 0.03 & 0 & 0.01 & 0.24 & 0.01 \\
\hline $24^{\mathrm{a}}$ & 0.11 & 0.09 & 0.03 & $>100$ & 62.1 & 0.06 & 0.03 & 0.61 & 2.27 \\
\hline 34 & 0 & 0.01 & 0.01 & 3.13 & 3.02 & 0 & 0.01 & 0.01 & 13.55 \\
\hline 38 & 0 & 0 & 0 & 3.89 & 0.66 & 0 & 0 & 0.05 & 0.3 \\
\hline 41 & 0.17 & 0 & 0 & 0 & 0 & 0 & 0 & 0.01 & 1.62 \\
\hline 56 & 0.12 & 0 & 0.01 & 0 & 0 & 0 & 0.01 & 0 & 0 \\
\hline $58^{\mathrm{a}}$ & 0 & 0.01 & 0 & 0.1 & 0 & 0 & 0 & 0 & 0 \\
\hline 59 & 0 & 0 & 0.01 & 0.02 & 0 & 0 & 1.35 & 0.01 & 0.49 \\
\hline $79^{\mathrm{a}}$ & 0.11 & 0 & 0.01 & 7.59 & 0 & 0 & 0.04 & 0.02 & 0 \\
\hline $87^{\mathrm{a}}$ & 0.19 & 0.01 & 0.15 & 0.04 & 0.01 & 0 & 0.02 & 0.03 & 0.02 \\
\hline 88 & 0.16 & 0.01 & 0.01 & 0.01 & 0 & 0 & 1.91 & 0.02 & 0.02 \\
\hline 91 & 0.07 & 0 & 0.01 & 1.1 & 2.27 & 1.02 & 0.02 & 0.78 & 0 \\
\hline $93^{\mathrm{a}}$ & 0.28 & 0.01 & 0.02 & 19.8 & 9.86 & 0.02 & 1.06 & 0.01 & 0.01 \\
\hline 99 & 0.03 & 0 & 0.01 & 21.4 & 0 & 0 & 0.02 & 0.05 & 1.11 \\
\hline $100^{\mathrm{a}}$ & 0.25 & 0.01 & 0.01 & 0.02 & 0 & 0.01 & 0.01 & 0 & 0 \\
\hline
\end{tabular}

aPatients in whom immunoblotting was performed. 
The mean (SD) age of patients was 24.1 (13.4) years (range, $5-57$ years), 52\% were female, $72 \%$ were adolescents or adults, and $97 \%$ and $78 \%$ had allergic rhinitis and asthma, respectively.

The percentages of patients with positive $\operatorname{sigE} \geq 0.35 \mathrm{kU}_{\mathrm{A}} / \mathrm{L}$ were as follows: Ole e 1, 73\%; Ole e 7, 52\%; Ole e 9, 34\%; Phl p 1, 61\%; Phl p 5, 27\%; Phl p 7, 6\%; Phl p 12, 17\%; Sal k 1, 30\%; and Cup s 1, 39\%. The allergic Olea profiles were as follows: $25 \%$ of patients were sensitized to Ole e 1, 7, and 9; $21 \%$ were sensitized to Ole e 1 and $7 ; 8 \%$ were sensitized to Ole e 1 and 9; and 6\% were monosensitized to Ole e 7 . In 20\% of cases, the patients showed negative sIgE to Ole e 1, 7, and 9 .

The sensitization profiles of patients with negative $\mathrm{sIgE}$ to Ole e 1, 7, and 9 are shown in the Table. Immunoblotting was performed in 9 of the patients for whom sufficient serum was available to test whether the difference between SPT and $\mathrm{sIgE}$ results was due to different allergens or isoforms of these allergens. Immunodetection results showed that 6 patients were weakly positive for Ole e 1, while no signal was detected in 4 patients (data no shown). Some of these patients may be sensitive to other allergens not considered in this study.

The Ole e 1-positive/Ole e 7 and 9-negative profile was more frequent in nonasthmatics than in asthmatics $(36.4 \%$ vs $14.1 \%, P=.0296)$, while asthmatic patients who showed a positive response to Ole e 1, 7, and 9 were more frequent than nonasthmatic patients with the same profile $(29.5 \%$ vs $9.1 \%, P=.0056)$.

The prevalence of asthma was significantly higher in patients sensitized to Ole e 1 (OR, 2.9; 95\%CI, 1.10-8.10; $P=.0276)$, Ole e 7 (OR, 7.2; 95\%CI, 2.22-23.33; $P=.0003)$, Phl p 5 (OR, 4.7, 95\%CI, 1.02-21.77; $P=.0321)$, and Sal k 1 (OR, 5.6, 95\%CI, 1.22-25.74 $P=.0153$ ). When the 4 allergens were analyzed together using a logistic regression model, only Ole e 7 and Phl p 5 retained a significant OR (4.98 [95\%CI, 1.43-17.38] and 5.11 [95\%CI, 1.00-26.10], respectively). However, when the analysis was carried out using a stepwise method, the only significant result was for Ole e 7 (OR, 7.2; 95\% CI, 2.22-23.33).

The olive pollen count in Jaen can reach up to 20000 grains $/ \mathrm{m}^{3}$, making it the region with the highest levels of olive tree pollen in Europe. In areas with low allergen pressure, Ole e 1 is the only marker of sensitization to olive [1], while in areas with high exposure, other allergens can be involved in the sensitization process.

In this study, no SIgE was detected against 3 olive pollen allergens in a large number of patients $(20 \%)$. Consequently, diagnosis based on conventional techniques may be insufficient for these patients, even considering that 4 of them could have positive SPT by sensitization to profilin or polcalcin and that positivity to Sal k 1 may have led to a positive SPT and the similarity between Sal k 1 and Ole e 11 (pectin methyl esterases). Therefore, determination of sIgE to both major and minor allergens should be included in the diagnostic routine of these patients. In areas such as Jaen, minor allergens cause genuine allergic sensitization. The fact that there are patients who are monosensitized to Ole e 7 is an indication that this allergen can induce an allergic reaction by itself. An association between sensitization profiles and clinical profiles has been established for perennial allergens [7]; however, for seasonal allergens such as grass, this association is not as clear [8]

Also important is the possible indication of AIT in these patients. The standardization of allergen extracts is based, at best, on the quantification of the major allergen. In patients who are negative for Ole e 1, 7, and 9, standardization should take other allergens into account, as sensitivity to Ole e 7 is associated with a higher incidence of adverse reactions, as shown elsewhere [9]. Strict control of allergen content may be crucial for good tolerance. A recent publication examined the influence of sensitization to minor allergens on the post-AIT outcome with an Olea allergen extract [10].

In conclusion, in areas with extreme pollen counts, minor allergens can behave as genuine markers of allergic sensitization. Consequently, diagnosis should include determination of sIgE to these allergens in order to establish adequate immunotherapy.

\section{Acknowledgments}

The statistical analysis was performed by BioClever SL, Barcelona, Spain.

\section{Funding}

The work in the corresponding author's laboratory is supported by the Spanish Ministry of Economy, Industry, and Competitiveness (SAF2011-26716 and SAF2014-53209-R).

\section{Conflicts of Interest}

Manuel Alcántara, Blanca Sáenz de San Pedro, Carmen Cañada, Miguel Ángel Muñoz, and Mayte Villalba declare that they have no conflicts of interest. Lucía Jimeno and Fernando de la Torre are employed by ALK-Abelló, SA, Madrid, Spain.

\section{References}

1. Barber D, de la Torre F, Feo F, Florido F, Guardia P, Moreno C, Quiralte J, Lombardero M, Villalba M, Salcedo G, Rodríguez R. Understanding patient sensitization profiles in complex pollen areas: a molecular epidemiological study. Allergy. 2008;63:1550-8.

2. Florido López JF, Quiralte Enríquez J, Arias de Saavedra JM, Sáenz B, Martín Casanez E. An allergen from Olea europea pollen (Ole e 7) is associated with plant-derived food anaphylaxis. Allergy. 2002;57:53-9.

3. Tordesillas L, Sirvent S, Díaz-Perales A, Villalba M, CuestaHerranz J, Rodríguez R, Salcedo G. Plant lipid transfer protein allergens: no cross-reactivity between those from foods and olive and Parietaria pollen. Int Arch Allergy Immunol. 2011;156:291-6.

4. Scala $E$, Abeni $D$, Pomponi D, Paganelli R, Locanto M, Giani M, Cecchi L, Asero R. Ole e 1, Ole e 7 and Ole e 9: Identifying distinct clinical subsets of olive tree-allergic patients. J Allergy Clin Immunol. 2016;137:62-630.

5. J Bousquet, van Cauwenberge P, Khaltaev N; Aria Workshop Group; World Health Organization. Allergic rhinitis and its impact on asthma. J Allergy Clin Immunol. 2001;108(5 Suppl):S147-S334. 
6. GEMA (Guía española para el manejo del asma). Arch Bronconeumol. 2009;45(Supl7):2-35.

7. Vidal C, Lojo S, Juangorena M, González-Quintela A. Association between asthma and sensitization to allergens of Dermatophagoides pteronyssinus. J Investig Allergol Clin Immunol. 2016;26:304-9.

8. Palao-Ocharán $\mathrm{P}$, Domínguez-Ortega J, Barranco P, DíazAlmirón M, Quirce S. Does the profile of sensitization to grass pollen allergens have clinical relevance? I Investig Allergol Clin Immunol. 2016;26:185-211.

9. Serrano P. Sensibilización a alérgenos minoritarios de Olea europea como causa de reacciones sistémicas por inmunoterapia alérgeno-específica. Doctoral Thesis, Córdoba: Facultad de Medicina, Universidad de Córdoba, 2007.

10. Peñuelas $E$, Serrano $P$, Barasona MJ, Saiz V, Fernández $L$, Moreno C. Sensitization to minor allergens has a direct influence on the outcome of subcutaneous immunotherapy in olive-allergic patients. J Investig Allergol Clin Immunol. 2016;26:185-211.

- Manuscript received October 18, 2016; accepted for publication December 19, 2016.

Fernando de la Torre

ALK-Abelló, S.A.

C/ Miguel Fleta, 19

28037 Madrid

E-mail: fernando.delatorremartinez@alk.net

\section{Drug Eruption Caused by Rosuvastatin}

Oda T, Sawada Y, Yamaguchi T, Ohmori S, Haruyama S, Yoshioka M, Okada E, Nakamura M

Department of Dermatology, University of Occupational and Environmental Health, Kitakyushu, Japan

J Investig Allergol Clin Immunol 2017; Vol. 27(2): 140-141 doi: 10.18176/jiaci.0136

Key words: Drug eruption. Rosuvastatin. Literature review.

Palabras clave: Erupción medicamentosa. Rosuvastatina. Revisión de la literatura.

Hyperlipidemia causes progressive atherosclerosis through physical injury to the endothelial cells of arteries and it also exacerbates arteriosclerosis. The annual incidence of hyperlipidemia is increasing and treatment is necessary to improve cardiovascular events. Statins are a class of antihyperlipidemic drugs that inhibit hydroxymethylglutaryl$\mathrm{CoA}$ (HMG-CoA) reductase, resulting in reduced lowdensity lipoprotein (LDL) cholesterol [1] and a lower incidence of coronary artery disease. Because of their strong antihyperlipidemic effects, various statin drugs are widely used for treatment. Rosuvastatin is one such drug with potent HMGCoA reductase inhibitory activity [2]. Although other statininduced drug eruptions have been reported, to our knowledge there have been no reports of cutaneous adverse events due to rosuvastatin in the English literature. We describe the first case of drug eruption caused by rosuvastatin and review similar cases reported for other statin drugs.

A 78-year-old woman noticed a small erythematous eruption on her extremities 1 month after the administration of rosuvastatin for hyperlipidemia. She gradually developed a generalized erythematous eruption and was referred to our department for evaluation. She had no history of drug hypersensitivity or other allergic diseases and reported no flu-like symptoms in recent years. Physical examination revealed small erythematous plaques and papules on her extremities (Figure A) and trunk; there was no mucosal involvement. A skin biopsy taken from an erythematous plaque revealed a lymphocytic and eosinophilic infiltration in the upper dermis (Figure B). Based on the clinical course, we speculated that the skin rash might be a drug eruption, possibly due to rosuvastatin. To investigate this suspicion, patch testing with rosuvastatin was performed and a positive reaction was observed at 48 hours for the $20 \%$ concentration. The skin eruption was diagnosed as a maculopapular-type drug eruption due to rosuvastatin. Two weeks after topical application of betamethasone butyrate propionate ointment and the discontinuation of rosuvastatin, the eruption improved.

We reviewed the literature and analyzed the clinical characteristics of our case and other statin-associated drug eruptions reported to date. To our knowledge, 32 cases, including ours, have been reported (Supplementary Table). 

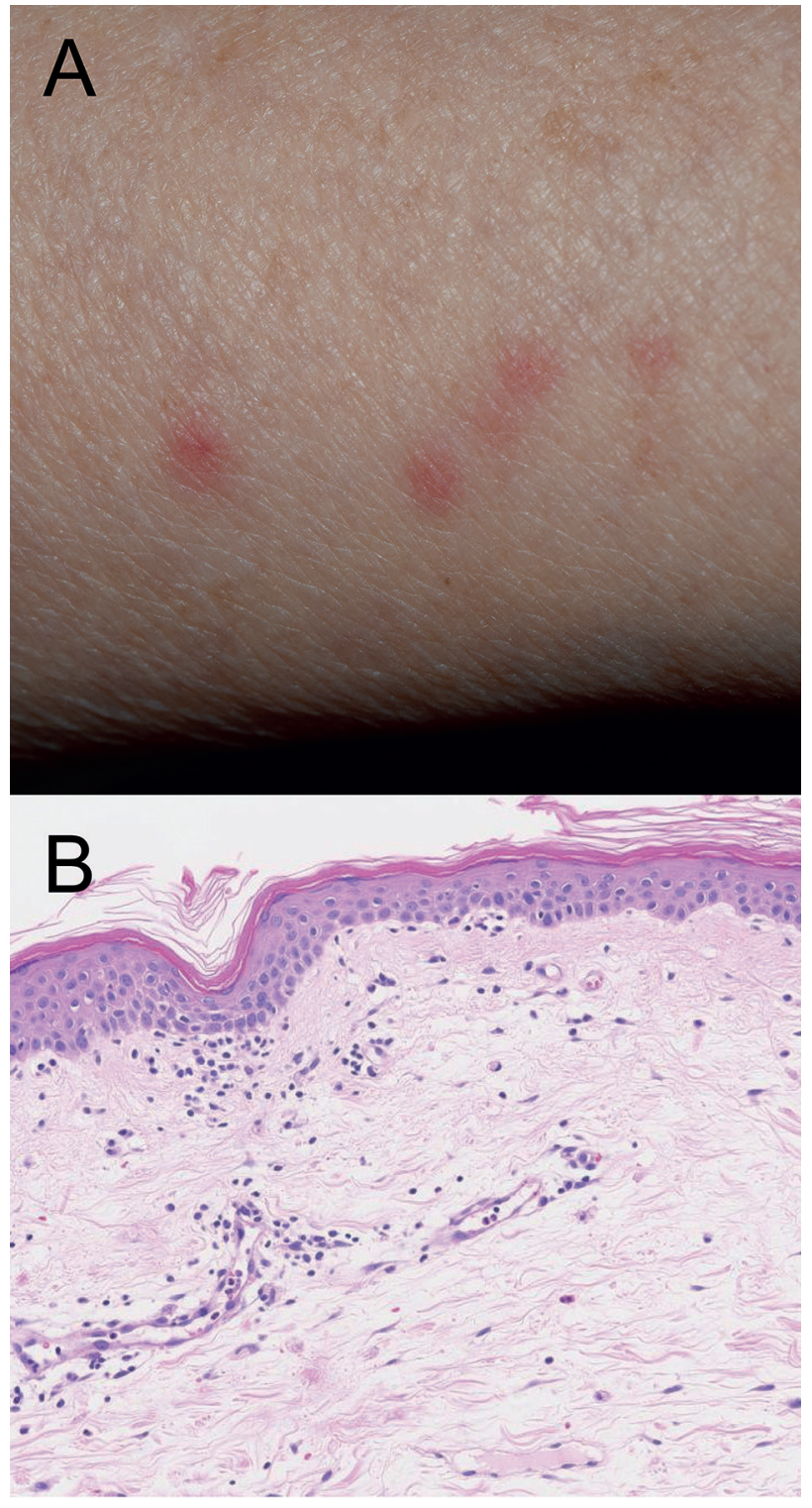

Figure. A, Small erythematous plaques and papules on the patient's right arm. B Histologic examination showing lymphocytic and eosinophilic infiltration in the upper dermis and around vessels.

The male to female ratio is $1.5: 1$, and the mean age is 63.8 years. The causative drugs were simvastatin ( $40.6 \%$ of cases), pitavastatin $(31.3 \%)$, atorvastatin $(18.8 \%)$, fluvastatin $(6.3 \%)$, and lovastatin, pravastatin, and rosuvastatin (3.1\% each). The most common eruption type was eczematous eruption. Interestingly, $31.3 \%$ of cases exhibited a lichenoid tissue reaction in the skin. Cross-reactivity is an important issue in the treatment of hyperlipidemia. One report described how a patient experienced photoallergy to simvastatin, a type 1 statin, but tolerated atorvastatin, a type 2 statin [3]. Another report described cross-reactivity between fluvastatin and rosuvastatin, both type 2 statins [4]. Cross-reactivity between different types of statins - atorvastatin (type 1) and simvastatin (type 2)- has also been reported [5].
We have reported the first case of drug eruption caused by rosuvastatin. Although the patient exhibited a relatively mild reaction, it should be kept in mind that rosuvastatin could cause severe cutaneous adverse events, similar to those reported for other statin agents. Further investigation is necessary to clarify the characteristics of rosuvastatin-induced drug eruption.

\section{Funding}

The authors declare that no funding was received for the present study.

\section{Conflicts of Interest}

The authors declare that they have no conflicts of interest.

\section{References}

1. Lopez LM. Managing hyperlipidemia: current and future roles of HMG-CoA reductase inhibitors. Am J Health Syst Pharm. 2002;59(12):1173-9; quiz 80-2.

2. McTaggart F, Buckett $L$, Davidson R, Holdgate G, McCormick A, Schneck D, Smith G, Warwick M. Preclinical and clinical pharmacology of Rosuvastatin, a new 3-hydroxy-3methylglutaryl coenzyme A reductase inhibitor. Am J Cardiol. 2001:87(5a):28b-32b.

3. Sommer M, Trautmann A, Stoevesandt J. Relief of photoallergy: atorvastatin replacing simvastatin. J Investig Allergol Clin Immunol. 2015;25(2):138-40.

4. Sebok B, Toth M, Anga B, Harangi F, Schneider I. Lichenoid drug eruption with HMG-CoA reductase inhibitors (fluvastatin and lovastatin). Acta Derm Venereol. 2004;84(3):229-30.

5. Huertas AJ, Ramirez-Hernandez M, Merida-Fernandez C, Chica-Marchal A, Pajaron-Fernandez MJ, Carreno-Rojo A. Fixed drug eruption due to atorvastatin. J Investig Allergol Clin Immunol. 2015;25(2):155-6.

Manuscript received October 17, 2016; accepted for publication December 29, 2016.

Yu Sawada

Department of Dermatology University of Occupational and Environmental Health

1-1 Iseigaoka, Yahatanishi-ku Kitakyushu 807-8555, Japan E-mail: long-ago@med.uoeh-u.ac.jp 
Anisakis Sensitivity in Italian Children: A Prospective Study

Tripodi $\mathrm{S}^{1}$, Pingitore $\mathrm{G}^{2}$, Calvani $\mathrm{M}^{3}$, Scala $\mathrm{G}^{4}$, Rodriguez-Perez $\mathrm{R}^{5}$, Sfika $\mathrm{I}^{1}$, Asero $\mathrm{R}^{6}$

${ }^{1}$ Pediatric Department and Pediatric Allergology Unit, Sandro Pertini Hospital, Rome, Italy

${ }^{2}$ Allergy Unit, Grassi Hospital, Rome, Italy

${ }^{3}$ Pediatric Unit, S. Camillo Forlanini Hospital, Rome, Italy

${ }^{4}$ U.O.S.D. Allergologia e Immunologia Clinica, Loreto Crispi Hospital, Naples, Italy

${ }^{5}$ Hospital La Paz Institute for Health Research, IdiPAZ, Madrid, Spain

${ }^{6}$ Allergy Unit, Clinica san Carlo, Paderno Dugnano, Italy

J Investig Allergol Clin Immunol 2017; Vol. 27(2): 142-143 doi: 10.18176/jiaci.0139

Key words: Food allergy. Children. Fish allergy. Anisakis simplex.

Palabras clave: Alergia alimentaria. Niños. Alergia a pescado. Anisakis simplex.

Ingestion of live larvae (larval stage 3 ) of the nematode Anisakis simplex in raw or undercooked seafood that has not been deep-frozen may lead to gastrointestinal infection, and, in genetically predisposed individuals, sensitization to the helminth's proteins [1]. In Italy, sensitization to Anisakis is mostly associated with ingestion of traditional marinated or poorly cooked fish [2], although it is sometimes detected in individuals with no apparent risk factors. The prevalence of sensitization and allergy to Anisakis in children living in endemic areas is unknown. We investigated a cohort of children living in areas of Italy where hypersensitivity to Anisakis is endemic [2].

We studied 443 consecutive children (boys/girls, 258/160; mean age, 9.3 years; range, $1-17$ years) presenting at 3 pediatric allergy centers in Rome and 1 center in Naples. A questionnaire was completed for all patients to detect possible risk factors for sensitization to Anisakis before the visit. All of the patients underwent skin prick testing (SPT) with a commercial extract of A simplex (2 mg protein/mL; ALK-Abelló) and with commercial extracts of house dust mites, codfish, shrimp, and cockroach (ALK-Abelló). In view of the well-known cross-reactivity between helminths, crustaceans, insects, and house dust mites [3], we only studied patients with unequivocal skin reactivity to Anisakis extract in the absence of any skin reactivity to house dust mite, shrimp, or cockroach in order to detect those who were genuinely sensitized to the helminth. Specific IgE to whole $A$ simplex extract was measured using ImmunoCAP (Thermo Fisher Scientific). Furthermore, IgE to available recombinant Anisakis allergens (Ani s 1, Ani s 5, Ani s 9, and Ani s 10) was detected using ELISA [4-7]. Immunoblot analysis with whole Anisakis extract was also performed, as previously described [7]. In keeping with a previous study from Italy [2], A simplex allergy was considered to be highly likely in the presence of a history of 1 or more allergic reactions that unequivocally followed the ingestion of fish and a positive SPT result to Anisakis and negative SPT result to fish. Patients with a positive SPT result to Anisakis but no clinical history of fish-induced reactions were considered to be sensitized but not allergic to the helminth.

In all, 20 children (boys/girls, 13/8; mean age, 10.9 years; range, 5-16 years) corresponding to approximately $4.5 \%$ of the study population were eventually considered to be genuinely sensitized to Anisakis (Table). Apart from a significantly older mean age $(P<.02)$, reactors did not differ from the control population in terms of prevalence of personal or familial consumption of raw, marinated, or undercooked fish, frequency of fishing as a hobby, or being in rooms where fish dishes were prepared. No Anisakis-sensitized child had a history of urticaria or gastroenteritis following ingestion of fish, and in no case did parents suspect that their son/ daughter had fish allergy, although episodes of abdominal pain during the previous 2 years were reported by the parents of 3 children. Interestingly, 6 of 18 sensitized children (33\%) had an aquarium at home, where fish and/or water turtles were bred. Since these data are not available for the general population, we do not know whether this represents a risk factor for sensitization to Anisakis.

The result of ImmunoCAP was positive in 11 cases, although specific IgE levels were often low. With ELISA, only 2 patients reacted to Ani s 1, 1 to Ani s 5, and 1 to Ani s 10, whereas no patients experienced hypersensitivity to Ani s 9. Immunoblot analysis revealed that sera from only 3 patients were positive and that all 3 showed IgE reactivity to a variable number of Anisakis proteins with a molecular weight ranging between $9 \mathrm{kDa}$ and $170 \mathrm{kDa}$. The serum from 1 additional patient showed weak reactivity at $25 \mathrm{kDa}$ only.

This is the first study specifically designed to assess the frequency of sensitization to Anisakis in children living in endemic areas. More than $4.5 \%$ of the children were genuinely sensitized to the parasite. Notably, this proportion is identical to that found in a larger study carried out in Italian adults [2] and suggests that sensitization to the parasite in endemic areas may occur at very young ages. Interestingly, Anisakis-sensitized children were significantly older than control children (the youngest was nearly 6 years old), suggesting that that the likelihood of sensitization increases over time and is most likely associated with a change in eating habits. However, none of the patients reported a history of urticaria or abdominal pain following ingestion of raw or marinated fish; this finding is in keeping with the fact that sensitization in this age group was mostly slight, as shown by the very low specific IgE levels recorded. The few children showing stronger sensitization reacted to defined major and minor Anisakis allergens such as Ani s 1, Ani s 5, and Ani s 10, although immunoblot analysis demonstrated $\mathrm{IgE}$ reactivity to other proteins as well. Of course, marinated and raw fish remain the most likely source of sensitization to the parasite in these children [2], although some sensitized children did not seem to have specific risk factors. Interestingly, 6 children had an aquarium at home where fish and/or turtles were bred; since sea fish-derived products and larvae are generally used to feed both freshwater and seawater fish, sensitization may sometimes occur via the 
Table. Physical and Immunological Features of Anisakis-Sensitive Children

\begin{tabular}{|c|c|c|c|c|c|c|c|c|c|}
\hline \multirow[b]{2}{*}{ No. } & \multirow[b]{2}{*}{ Sex } & \multirow[b]{2}{*}{ Age, y } & \multirow[b]{2}{*}{ Wheal Size, $\mathrm{mm}$} & \multirow[b]{2}{*}{$\mathrm{CAP}, \mathrm{kU}_{\mathrm{A}} / \mathrm{mL}$} & \multicolumn{4}{|c|}{ ELISA (OD450) } & \multirow[b]{2}{*}{ Immunoblot IgE, $\mathrm{kDa}$} \\
\hline & & & & & Ani s 1 & Ani s 5 & Ani s 9 & Ani s 10 & \\
\hline 1 & M & 14.3 & 3 & Neg & $\mathrm{Neg}$ & Neg & Neg & Neg & \\
\hline 2 & M & 13.9 & 6 & Neg & Neg & Neg & Neg & Neg & \\
\hline 3 & M & 11.4 & 9 & 0.18 & $\mathrm{Neg}$ & Neg & Neg & Neg & 25 \\
\hline 4 & M & 11.3 & 5 & $\mathrm{Neg}$ & Neg & Neg & $\mathrm{Neg}$ & Neg & \\
\hline 5 & M & 11.6 & 6.5 & 12.1 & 0.24 & Neg & Neg & 0.1235 & $10,26,30,38,116$ \\
\hline 6 & M & 12.2 & 6 & 0.26 & Neg & Neg & Neg & Neg & \\
\hline 7 & M & 10.8 & 5 & $\mathrm{Neg}$ & Neg & Neg & Neg & Neg & \\
\hline 8 & $\mathrm{~F}$ & 7.6 & 5 & Neg & Neg & Neg & Neg & $\mathrm{Neg}$ & \\
\hline 9 & $\mathrm{~F}$ & 9.2 & 5 & Neg & Neg & Neg & Neg & Neg & \\
\hline 10 & $\mathrm{~F}$ & 8.42 & 4 & 0.13 & Neg & Neg & Neg & Neg & \\
\hline 11 & $\mathrm{~F}$ & 10.3 & 3.9 & 0.57 & Neg & Neg & $\mathrm{Neg}$ & Neg & \\
\hline 12 & $\mathrm{~F}$ & 11.9 & 5 & 0.15 & Neg & Neg & Neg & Neg & \\
\hline 13 & $\mathrm{~F}$ & 13.9 & 6 & 0.1 & Neg & Neg & Neg & Neg & \\
\hline 14 & M & 9 & 6 & 2.82 & Neg & Neg & Neg & Neg & $20,25,50,170$ \\
\hline 15 & M & 5.75 & 4 & $\mathrm{Neg}$ & $\mathrm{Neg}$ & $\mathrm{Neg}$ & $\mathrm{Neg}$ & $\mathrm{Neg}$ & \\
\hline 16 & M & 9.6 & 4.5 & 0.1 & Neg & Neg & $\mathrm{Neg}$ & Neg & \\
\hline 17 & $\mathrm{~F}$ & 7 & 3.6 & $\mathrm{Neg}$ & Neg & Neg & Neg & Neg & \\
\hline 18 & M & 11 & 5 & $\mathrm{Neg}$ & Neg & Neg & $\mathrm{Neg}$ & Neg & \\
\hline 19 & M & 16 & 7 & 14.3 & 0.4885 & 0.2235 & Neg & Neg & $9,12,30,36,38,110$ \\
\hline 20 & M & 14 & 5 & 1.05 & Neg & Neg & Neg & Neg & \\
\hline
\end{tabular}

respiratory tract or through the skin by handling such materials, although further studies are needed to confirm this hypothesis.

In conclusion, this study shows that sensitization to Anisakis in endemic areas is equally frequent in children and in adults. Pediatricians living in such areas should bear this in mind when evaluating young patients with acute gastroenterological or skin symptoms Risk factors other than ingestion of marinated fish could be involved in sensitization to Anisakis.

\section{Funding}

The authors declare that no funding was received for the present study.

\section{Conflicts of Interest}

The authors declare that they have no conflicts of interest.

\section{References}

1. Ishikura H, Kikuchi K, Nagasawa K, Ooiwa T, Takamiya H, Sato N, Sugane K. Anisakidae and Anisakidosis. Prog Clin Parasitol. 1993;3:43-102.

2. AAITO-IFIACI Anisakis Consortium. Anisakis hypersensitivity in Italy: prevalence and clinical features: a multicenter study. Allergy. 2011;66:1563-9.

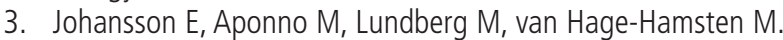
Allergenic cross-reactivity between the nematode Anisakis simplex and the dust mites Acarus siro, Lepidoglyphus destructor, Tyrophagus putrescentiae, and Dermatophagoides pteronyssinus. Allergy. 2001;56:660-6.

4. Rodriguez-Perez $R$, Caballero ML, Gonzalez-Munoz $M_{\text {, }}$ Rodriguez-Mahillo A, Moneo I. Cloning and expression of a biologically active Anisakis simplex allergen Ani s 1 in the yeast Pichia pastoris. Mol Biochem Parasitol. 2007;154:1158.

5. Rodriguez-Perez R, Moneo I, Rodriguez-Mahillo A, Caballero M L. Cloning and expression of Ani s 9, a new Anisakis simplex allergen. Mol Biochem Parasitol. 2008;159:92-7.

6. Caballero ML, Umpierrez A, Moneo I, Rodriguez-Perez R. Ani s 10, a new Anisakis simplex allergen: cloning and heterologous expression. Parasitol Int. 2011;60:209-12.

7. Caballero ML, Asero R, Antonicelli L, Kamberi E, Colangelo C, Fazii P, de Burgos C, Rodriguez-Perez R. Anisakis allergy component-resolved diagnosis: clinical and immunologic differences between, patients from Italy and Spain. Int Arch Allergy Immunol. 2013;162:39-44.

Manuscript received December 21, 2016; accepted for publication January 4, 2017.

Riccardo Asero

Ambulatorio di Allergologia, Clinica San Carlo Via Ospedale 21, 20037 Paderno Dugnao (MI), Italy E-mail: r.asero@libero.it 


\section{Drug Reaction With Eosinophilia and Systemic Symptoms (DRESS) Syndrome in Children: A Case Report}

Mattoussi N, Ben Mansour A, Essadam L, Guedri R, Fitouri Z, Ben Becher S

Université de Tunis El Manar, Faculty of Medicine and Pediatrics Department, Bechir Hamza Children's Hospital, Tunis, Tunisia

J Investig Allergol Clin Immunol 2017; Vol. 27(2): 144-146 doi: 10.18176/jiaci.0140

Key words: DRESS syndrome. RegiSCAR. Vancomycin. Child.

Palabras clave: Síndrome DRESS. RegiSCAR. Vancomicina. Niño.

Adverse drug reactions affecting the skin are common. Cutaneous hypersensitivity reactions range in severity, from mild reactions to severe cutaneous adverse reactions (SCARs). Drug reaction with eosinophilia and systemic symptoms (DRESS) syndrome is a distinct SCAR characterized by a potentially life-threatening hypersensitivity reaction with extensive rash, eosinophilia, and internal organ involvement occurring most commonly 2-6 weeks after initiation of medication [1]. In children, DRESS syndrome is rare and probably underdiagnosed [2]. Here, we report a rare case of DRESS syndrome induced by vancomycin in a 14-year-old boy.

The patient had sickle cell thalassemia $(\mathrm{S} \beta)$ and was admitted to our clinic with fever and upper left quadrant pain. Laboratory findings showed leukocytosis $\left(26050 / \mathrm{mm}^{3}\right)$, neutrophilia, and elevated C-reactive protein $(209 \mathrm{mg} / \mathrm{L})$. Abdominal ultrasound revealed heterogeneous splenomegaly indicative of onset of a microabscess or an extended splenic infarction. The patient was treated with hydration, paracetamol, cefotaxime $(200 \mathrm{mg} / \mathrm{kg} / \mathrm{d})$, and vancomycin $(60 \mathrm{mg} / \mathrm{kg} / \mathrm{d})$. The fever remitted after 4 days of antibiotics, and inflammation gradually resolved.

On day 13 of therapy with the 2 antibiotics, the patient presented again with fever $\left(39^{\circ} \mathrm{C}-40^{\circ} \mathrm{C}\right)$, odynophagia, and diffuse lymphadenopathy in the cervical, axillar, and inguinal areas. The cervical nodes were voluminous (up to $4 \mathrm{~cm}$ in diameter) and tender. Four days later, he presented poor general status, periorbital edema, and pruritic maculopapular rash located initially on the face and trunk before becoming generalized. Laboratory tests revealed a white blood cell count of $27100 / \mathrm{mm}^{3}$ with very high counts for lymphocytes $\left(7300 / \mathrm{mm}^{3}\right)$, mononuclear cells $\left(1600 / \mathrm{mm}^{3}\right)$, and eosinophils $\left(5800 / \mathrm{mm}^{3}\right)$, as well as hepatic cytolysis (AST, $341 \mathrm{IU} / \mathrm{L}$; ALT, $313 \mathrm{IU} / \mathrm{L})$ and hypergammaglobulinemia $(29.4 \mathrm{~g} / \mathrm{L})$. The patient was diagnosed with DRESS syndrome, therapy with vancomycin and cefotaxime was stopped, and cetirizine was prescribed. As there was no pulmonary, cardiac, or renal involvement and the hepatic disorder was mild, we chose to maintain the antihistamine with no other medication and to monitor our patient.

Concomitant serology testing for HHV-6 revealed IgM and $\mathrm{IgG}$ antibodies, thus indicating a reactivation.
The patient improved progressively with resolution of fever, desquamation, regression of lymphadenopathy, and normalization of hepatic enzymes. After 6 months, patch testing with vancomycin and cefotaxime was positive for vancomycin and negative for cefotaxime. Oral challenge testing with cefuroxime was well tolerated. We used cefuroxime to carry out an oral challenge test because of side chain homology at position $\mathrm{C} 3$ between cefotaxime and cefuroxime and therefore possible cross-reactivity between the 2 drugs [3]. The patient was sent an allergy card for vancomycin.

Mild adverse cutaneous reactions to drugs are common and have multiple clinical features. Such reactions affect up to $2 \%-3 \%$ of all hospitalized patients [1]. DRESS syndrome is characterized by a potentially life-threatening hypersensitivity reaction with extensive rash, fever, and internal organ involvement (liver and kidney) occurring most commonly 2-6 weeks after initiation of a medication. The incidence of this syndrome is estimated to range from 1 in 1000 to 1 in 10000 drug exposures [1]. Since the mortality rate of DRESS syndrome can reach $10 \%$, it is very important to recognize this syndrome and manage it as soon as possible [2].

The diagnosis of DRESS is mainly clinical [4]. The syndrome typically begins with prodromal symptoms of pruritus and fever $\left(38^{\circ} \mathrm{C}\right.$ to $\left.40^{\circ} \mathrm{C}\right)$. After several days, a descending pruritic maculopapular rash appears and may progress to erythroderma involving almost the entire surface of the skin [5]. The liver is the most frequently affected organ in DRESS syndrome (more than $70 \%$ of cases). Involvement ranges from a transient increase in liver enzymes to liver necrosis with fulminant hepatic failure [6]. Reactivation of HHV-6 has been shown to cause liver failure [1]. Consistent with these data, the patient we report on presented significant cytolysis with concomitant presence of anti-HHV-6 IgM, suggesting that hepatitis may be secondary to reactivation of HHV-6 [7].

Although the etiology of DRESS is poorly understood, genetic susceptibility markers have been identified within the HLA complex. According to Fernando [7], modification of host antigens by haptens (drugs or their metabolites) or noncovalent drug binding to endogenous proteins (the $p-i$ concept) may drive proinflammatory immune responses. The concomitant detection of herpes virus and the recent demonstration of Epstein-Barr virus-specific immune responses in DRESS patients has also been considered a viral trigger of DRESS.

The most frequently implicated drugs in DRESS syndrome are aromatic anticonvulsants, allopurinol, and sulfamids $[1,5]$. However the list of potential causative agents is growing and now includes antiviral, biologic, and nonsteroidal antiinflammatory, antimicrobial drugs $[1,2]$. A recent study of DRESS syndrome among inpatients at Massachusetts General Hospital found that vancomycin was involved in 5 of 6 cases identified over 18 months. The authors conclude that the causative agents of DRESS syndrome in an inpatient setting likely differ from those seen in the general population and point to the importance of recognizing vancomycin as a common cause of inpatient DRESS syndrome [8].

There are relatively few articles on DRESS syndrome in children [1]. The rare pediatric reports of vancomycin-induced DRESS syndrome describe a life-threatening condition with 
Table. Investigational Findings Before Starting Vancomycin, After 3 Weeks of Vancomycin, and After Discontinuation of Vancomycin

\begin{tabular}{|c|c|c|c|}
\hline Investigations & $\begin{array}{l}\text { Before Starting } \\
\text { Vancomycin }\end{array}$ & $\begin{array}{l}\text { At } 3 \mathrm{Wk} \text { of } \\
\text { Vancomycin }\end{array}$ & $\begin{array}{c}\text { After Discontinuation } \\
\text { of Vancomycin }\end{array}$ \\
\hline Hemoglobin, \% & 6.9 & 7.2 & 8 \\
\hline Total leukocyte count, cells $/ \mathrm{mm}^{3}$ & 26050 & 27100 & 11700 \\
\hline Lymphocytes $/ \mathrm{mm}^{3}$ & 11000 & 7300 & 6300 \\
\hline Eosinophils $/ \mathrm{mm}^{3}$ & 400 & 5800 & 700 \\
\hline Atypical lymphocytes & 0 & $6 \%$ & $1 \%$ \\
\hline Platelets $/ \mathrm{mm}^{3}$ & 178000 & 240000 & 250000 \\
\hline Urea, mmol/dL & 5 & 1,91 & 2 \\
\hline Creatinine, $\mu \mathrm{mol} / \mathrm{dL}$ & 30 & 20 & 20 \\
\hline Alanine aminotransferase & 72 & 353 & 88 \\
\hline Aspartate aminotransferase & 32 & 341 & 56 \\
\hline Total bilirubin & 24 & 20 & 18 \\
\hline Alkaline phosphatase & 30 & 25 & 28 \\
\hline Antinuclear antibody & Negative & Negative & Negative \\
\hline \multicolumn{4}{|l|}{ Patch test results } \\
\hline & & $\begin{array}{l}\text { Patch test to } \\
\text { vancomycin: positive } \\
\text { reaction }\end{array}$ & $\begin{array}{l}\text { Patch test to } \\
\text { vancomycin: positive } \\
\text { reaction }\end{array}$ \\
\hline
\end{tabular}

acute liver failure, aggravated encephalopathy, and azotemia necessitating liver transplantation in one case and frank and refractory shock in another case [9].

It is clear that the patient in the present study developed DRESS syndrome fulfilling all of the inclusion criteria of the European Registry of Severe Cutaneous Adverse Reactions (RegiSCAR) Study Group and Japanese Consensus Group (Table) [6].

The benign outcome of vancomycin-induced DRESS syndrome in the present patient confirms the broad spectrum of presentation of this syndrome in children and highlights that prompt withdrawal of the culprit drug is the main step toward complete recovery. Awareness of this drug reaction by pediatricians is crucial in order to avoid delayed diagnosis and poor outcome and to ensure long-term follow up of patients, since autoimmune disease can develop several months to years after clinical resolution of DRESS syndrome [10].

DRESS syndrome should be monitored systematically in patients receiving antibiotics, especially vancomycin. Withdrawal of the culprit drug should be discussed at the onset of rash, even before onset of systemic involvement, and before elimination of other possible diagnoses (eg, viral infection, autoimmune disorder, primitive or secondary hypereosinophilia syndrome, and pseudolymphoma). Further reports are needed to determine the incidence of DRESS syndrome in children and the extent to which antibiotics are involved in this syndrome in the pediatric population.

\section{Funding}

The authors declare that no funding was received for the present study.

\section{Conflicts of Interest}

The authors declare that they have no conflicts of interest.

\section{References}

1. Agnik P, Sukanta S, Arunava B, Syed MN, Santanu KT. A rare case of DRESS syndrome caused by vancomycin. J Acute Med. 2015;5:74-6.

2. Irga N, Kosiak W, Jaworski R, Zielinski J, AdamkiewiczDrozynska E. Pediatrician! Do you know the symptoms of 
DRESS syndrome? A Case report of 4-year-old girl. Pediatr Emerg Care. 2013;29:504-7.

3. Mirakian R1, Leech SC, Krishna MT, Richter AG, Huber PA, Farooque S, Khan N, Pirmohamed M, Clark AT, Nasser SM. Management of allergy to penicillins and other beta-lactams. Clin Exp Allergy. 2015 Feb;45(2):300-27.

4. Arruti N, Villarreal O, Bernedo N, Audicana MT, Velasco M, Uriel O, Martinez A, Bellón T. Positive Allergy Study (Intradermal, Patch, and Lymphocyte Transformation Tests) in a Case of Isoniazid-Induced DRESS. J Investig Allergol Clin Immunol. 2016;Vol.26(2):119-20.

5. Neuman MG, McKinney KK, Nanau RM, Kong V, Malkiewicz I, Mazulli T, Moussa G, Cohen LB. Drug induced severe adverse reaction enhanced by human herpes virus- 6 reactivation. Transl Res. 2013 May; 161(5):430-40.

6. R Cabañas, O Calderón, E Ramírez, A Fiandor, N Prior, T Caballero, P Herránz, I Bobolea, MC López-Serrano, S Quirce, T Bellón. Piperacillin-Induced DRESS: Distinguishing Features Observed in a Clinical and Allergy Study of 8 Patients. J Investig Allergol Clin Immunol. 2014; Vol. 24(6):425-30.

7. Fernando SL. Drug-reaction eosinophilia and systemic symptoms and drug-induced hypersensitivity syndrome. Australas J Dermatol. 2014 Feb;55(1):15-23.

8. Vinson AE, Dufort EM, Willis MD, Eberson CP, Harwell JI. Drug rash, eosinophilia and systemic syndrome: two pediatric cases demonstrating the range of severity in presentation- A case of vancomycin-induced drug hypersensitivity mimicking toxic shock syndrome and a milder case induced by minocycline. Pediatr Crit Care Med. 2010 Jul;11(4):e38-43.

9. Descamps $V$, Ranger-Rogez S. DRESS syndrome. Joint Bone Spine. 2014;81(1):15-21.

10. Hoetzenecker W, Nägeli $M$, Mehra $E T$, Jensen AN, Saulite I, Schmid-Grendelmeier P, Guenova E, Cozzio A, French LE. Adverse cutaneous drug eruptions: current understanding. Semin Immunopathol. 2016;38(1):75-86.

Manuscript received June 24, 2016; accepted for publication January 10, 2017.

Nadia Mattoussi

Bechir Hamza Hospital 1029, Av Bab Saâdoun

Tunis, Tunisia

E-mail: mattoussi.nadia@gmail.com
Total and Honeybee Venom-Specific Serum IgG4 and IgE in Beekeepers

Carballo I ${ }^{1}$, Carballada $\mathrm{F}^{2}$, Nuñez-Orjales $\mathrm{R}^{2}$, Martín-Lázaro $\mathrm{J}^{2}$, Vidal $\mathrm{C}^{3}$, Gonzalez-Quintela $\mathrm{A}^{1}$

${ }^{I}$ Department of Internal Medicine, Hospital and University of Santiago de Compostela, Santiago de Compostela, Spain

${ }^{2}$ Department of Allergy, Lucus Augusti Hospital, Lugo, Spain

${ }^{3}$ Department of Allergy, Hospital and University of Santiago de Compostela, Santiago de Compostela, Spain

J Investig Allergol Clin Immunol 2017; Vol. 27(2): 146-148 doi: 10.18176/jiaci.0141

Key words: IgG4. IgE. Beekeepers. Bee venom. Allergy.

Palabras clave: IgG4. IgE. Apicultores. Veneno de abeja. Alergia.

The function of the fourth subclass of immunoglobulin $\mathrm{G}$ (IgG4) is not completely understood. Circulating IgG4 molecules can be asymmetric, ie, the 2 antigen-binding sites in IgG4 molecules may be different, resulting in bispecificity [1] In allergic disorders, IgG4 can block the stimulation of mast cells by competing for allergen with membrane-bound $\operatorname{IgE}[1]$. The development of allergen-specific IgG4 (sIgG4), whether spontaneously or after allergen immunotherapy, indicates the activation of tolerance-inducing mechanisms [1]. Thus, the determination of sIgG4 may be useful for assessing the efficacy of immunotherapy [1]. In addition to determination of sIgG4, measurement of total serum IgG4 has become clinically relevant, because high serum IgG4 concentrations are a diagnostic criterion for IgG4-related disease [2]. IgG4related disease is a new concept that integrates many old diseases characterized by inflammation and fibrosis of 1 or more organs accompanied by a lymphoplasmacytic infiltrate rich in IgG4-positive plasma cells [2]. Intriguingly, IgG4related disease is related to allergic disorders [2].

Beekeepers are a suitable population for investigating serum IgG4 responses [3-5], since they are heavily exposed to stings and are therefore at high risk for developing honeybee venom (HBV) anaphylaxis. However, only a limited percentage of beekeepers develop severe anaphylaxis, because multiple stings act as natural immunotherapy, by increasing HBV-specific IgG4 (HBV-sIgG4) in serum [3-5]. To the best of our knowledge, the contribution of HBV-sIgG4 to total IgG4 has not yet been studied in individuals who are heavily exposed to HBV. Moreover, data on HBV-sIgG4 in general populations are lacking. This study sought to investigate total and HBV-specific serum IgG4 in beekeepers and controls. IgG4 concentrations were compared with those of total and HBV-specific serum IgE.

The study took advantage of a survey of beekeepers [6] conducted in northwest Spain $(\mathrm{n}=158,81 \%$ men, median age 57 years, range $23-88$ years). All participants completed a physician-administered structured questionnaire to determine beekeeping activities, sting episodes, and reactions to stings. 
Reactions to the last recorded sting were classified as none, small local $(<10 \mathrm{~cm})$, large local $(\geq 10 \mathrm{~cm}$, typically lasting $>24$ hours), or systemic. Individuals drawn from the general adult population in the same area $(n=465,44 \%$ men, median age 54 years, range 18-92 years) [7] were used as controls. Fifty-four percent of beekeepers and $75 \%$ of controls lived in a rural environment. Total serum IgG4 was measured based on turbidimetry in a SPAPLUS analyzer (Binding Site Limited). Total serum IgE was assayed using the IMMULITE 2000 system (Siemens). HBV-sIgE and HBV-sIgG4 were assayed using the ImmunoCAP-250 system (Phadia). Total IgG4, total $\mathrm{IgE}$, and $\mathrm{HBV}-\mathrm{sIgE}$ concentrations in controls were reported elsewhere [7-9], as were total IgE, HBV-sIgE, and HBVsIgG4 in beekeepers [6]. The analysis was performed using nonparametric approaches (Mann-Whitney test, Spearman
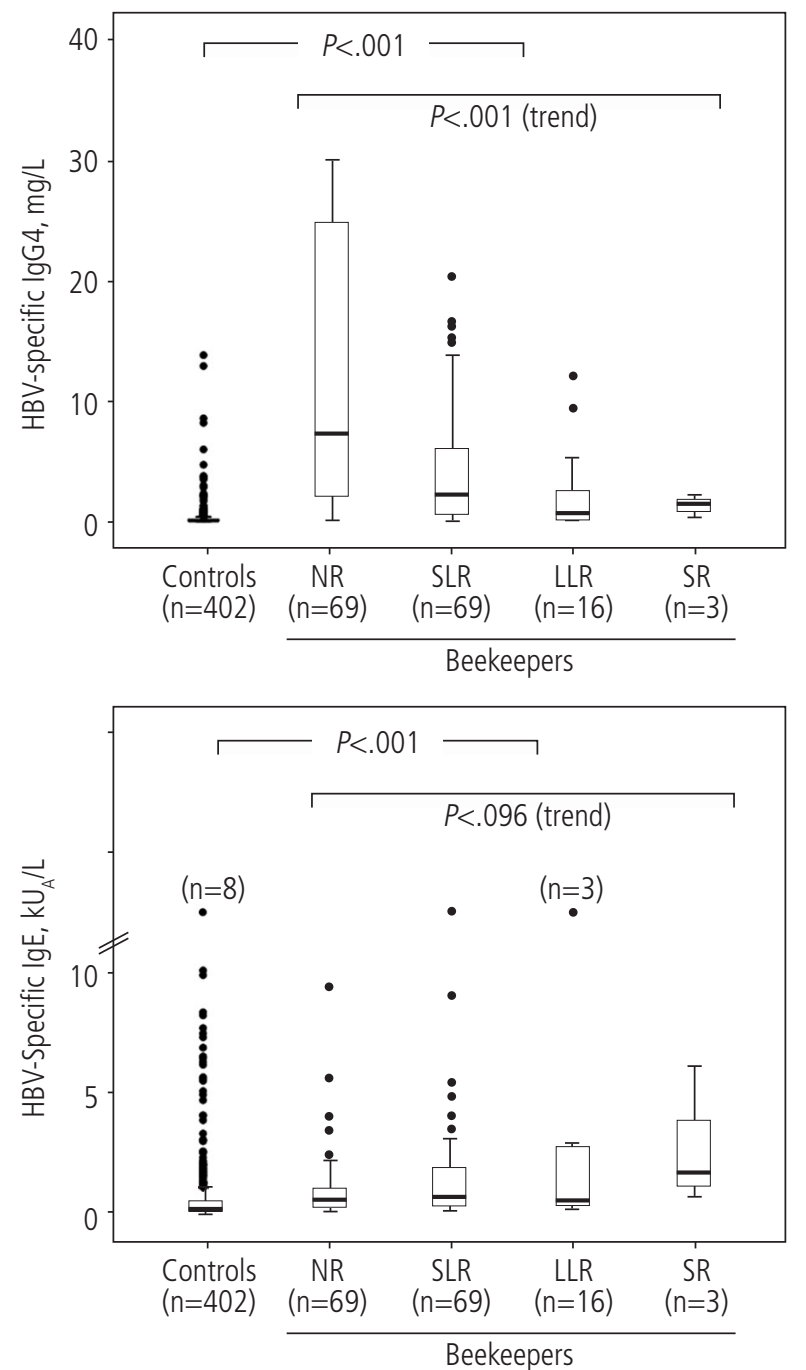

rank correlation, and Jonckheere-Terpstra test for trend). The study was reviewed and approved by the regional ethics committee.

Serum concentrations of total and HBV-specific IgG4 and $\mathrm{IgE}$ in beekeepers (stratified by type of reaction to the last recorded sting) and controls are depicted in the Figure. HBV-sIgG4 concentrations were higher in beekeepers (median [IQR], 3.06 [0.81-3.6] mg/L; absolute range, 0.02-30.0 mg/L) than in controls (median 0.07 [0.03-0.17] $\mathrm{mg} / \mathrm{L}$; absolute range, $0-13.8 \mathrm{mg} / \mathrm{L} ; P<.001)$. Among beekeepers, HBV-sIgG4 concentrations were highest among those who reported no reaction to stings. In general, the more severe the reaction to the sting, the lower the concentration of HBV-sIgG4 (Figure). The concentration of HBV-sIgG4 in beekeepers was positively correlated with the number of years beekeeping (rho, 0.365 ;
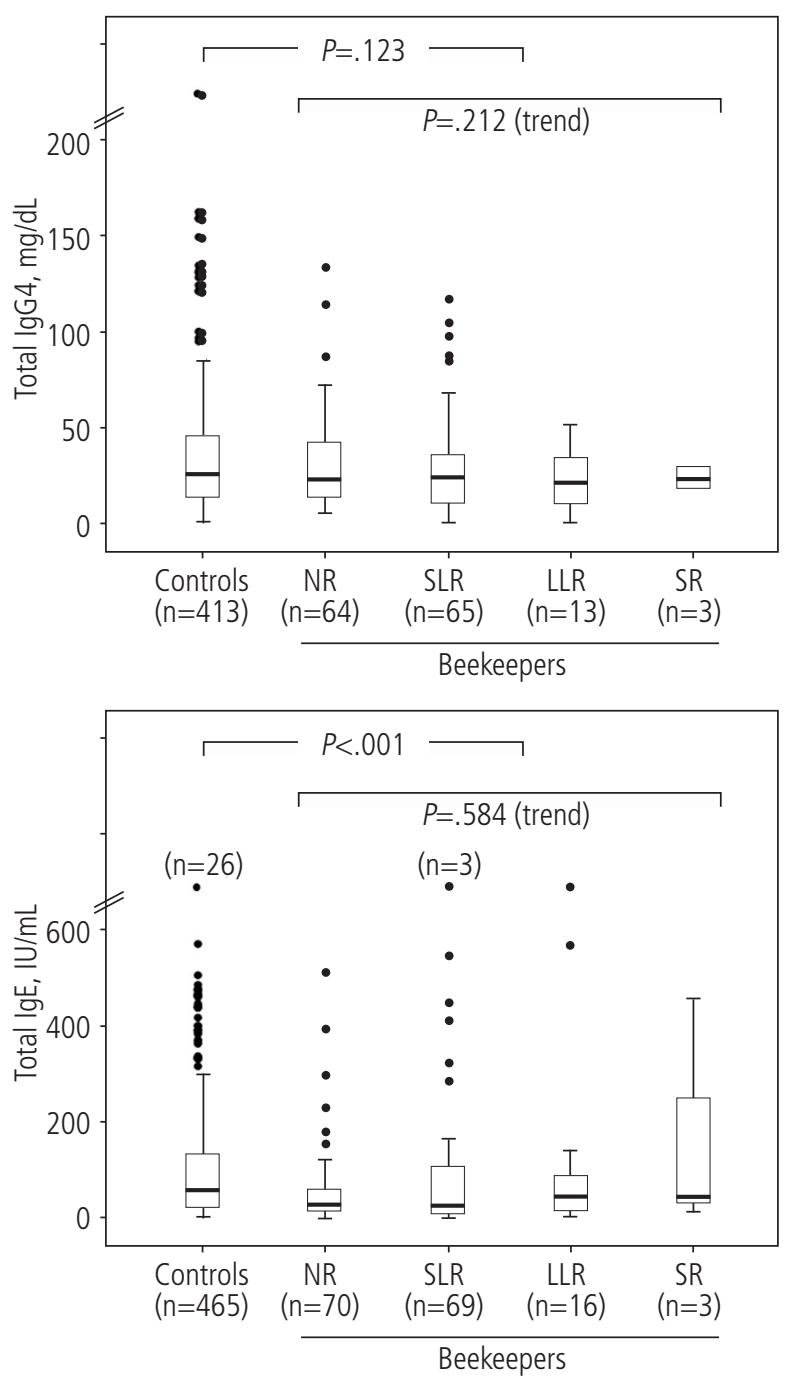

Figure. Serum concentrations of honeybee venom (HBV)-specific lgG4, HBV-specific lgE, total lgG4, and total IgE in controls and in beekeepers, stratified by reactions to the last recorded sting. Note that total lgG4 values were not available for 13 beekeepers and 52 controls; HBV-specific lgG4 values were not available for 1 beekeeper and 63 controls; HBV-specific lgE values were not available for 8 controls. LLR indicates large local reaction; NR, no reaction; SLR, small local reaction; SR, systemic reaction. 
$P=.014$ ), number of beehives (rho, $0.485 ; P<.001$ ), average number of bee stings per year (rho, $0.365, P<.001$ ), and number of bee stings during the previous year (rho, 0.506; $P<.001$ ). These indicators of exposure to $\mathrm{HBV}$ were not correlated with HBV-sIgE, total IgE, or total IgG4 (data not shown). A correlation was recorded between HBV-sIgG4 and total IgG4 in beekeepers (rho, $0.245 ; P=.003$ ) and controls alike (rho, $0.528, P<.001)$. The estimated proportion of total HBV-sIgG4 over total IgG4 was higher in beekeepers than in controls (median, 1.5\% [range, 0\%-30\%] vs median, 0.03\% [range, $0 \%-5 \%$ ] respectively, $P<.001)$. However, total IgG4 did not differ significantly between beekeepers and controls and was not associated with severity of reaction to stings (Figure). The concentration of HBV-sIgE was higher in beekeepers than in controls but was not significantly correlated with the severity of the sting reaction, although HBV-sIgE tended to be higher in beekeepers with more severe reactions (Figure). Total serum IgE was lower in beekeepers than in controls (Figure). The proportion of atopic individuals (ie, those with a positive skin prick test results to a panel of common aeroallergens in the area) was $22 \%$ in beekeepers and $26 \%$ in controls [6,7]. The negative association between beekeeping and lower IgE concentrations was independent of both age and atopic status (data not shown).

The results presented here are consistent with a tolerogenic role of HBV-sIgG4, namely, high concentrations of HBV-sIgG4 were associated with less severe sting reactions in beekeepers. Conversely, high concentrations of HBV-sIgE tended to be associated with a greater severity of sting reactions. These results generally confirm those of previous studies $[3-5,10]$. Intriguingly, total serum IgE was lower in beekeepers than in controls. Serum concentrations of HBV-sIgG4 and HBVsIgE were higher in beekeepers than in controls. Of note, a sizeable proportion of control individuals had detectable low concentrations of HBV-sIgG4. This finding may be important, because previous studies on HBV-sIgG4 included few controls $[4,5]$ and, to the best of our knowledge, no previous studies have investigated HBV-sIgG4 concentrations in the general population.

Total serum IgG4 concentrations did not differ significantly between beekeepers and controls. Serum concentrations of HBV-sIgG4 were correlated with those of total IgG4 in both beekeepers and controls. The contribution of HBV-sIgG4 to total IgG4 was higher in beekeepers than in controls, but the proportion of HBV-sIgG4 in relation to total IgG4 was small in both groups. Accordingly, beekeeping activities do not affect the clinical interpretation of total IgG4 concentrations.

\section{Funding}

This study was supported by a grant from the Instituto de Salud Carlos III (Spanish Ministry of Health, PI13/2549) and FEDER funds.

\section{Conflicts of Interest}

The authors declare that they have no conflicts of interest.

\section{References}

1. Aalberse RC, Stapel SO, Schuurman J, Rispens T. Immunoglobulin G4: an odd antibody. Clin Exp Allergy. 2009;39:469-77.

2. Stone JH, Zen Y, Deshpande V. IgG4-related disease. N Engl J Med. 2012;366:539-51.

3. Nakagawa T, Miyamoto T. The role of IgG4 as blocking antibodies in asthmatics and in beekeepers. Int Arch Allergy Appl Immunol. 1985;77:204-5.

4. Hayashi $Y$, Hirata $H$, Watanabe M, Yoshida N, Yokoyama T, Kakuta T, Murayama Y, Sugiyama K, Arima M, Fukushima Y, Fukuda T, Ishii Y. Usefulness of specific-lgG4 to Hymenoptera venom in the natural history of hymenoptera stings. J Investig Allergol Clin Immunol. 2014;24:192-4.

5. Varga EM, Kausar F, Aberer W, Zach M, Eber E, Durham SR, Shamji MH. Tolerant beekeepers display venom-specific functional IgG4 antibodies in the absence of specific lgE. J Allergy Clin Immunol. 2013;131:1419-21.

6. Carballada FJ, Gonzalez-Quintela A, Nuñez R, Vidal C, Boquete $M$. Low prevalence of $\mathrm{lg} E$ to cross-reactive carbohydrate determinants in beekeepers. J Allergy Clin Immunol. 2011;128:1350-2.

7. Gonzalez-Quintela A, Gude F, Boquete O, Rey J, Meijide LM, Suarez F, Fernandez-Merino MC, Perez LF, Vidal C. Association of alcohol consumption with total serum immunoglobulin $E$ levels and allergic sensitization in an adult population-based survey. Clin Exp Allergy. 2003;33:199-205.

8. Gonzalez-Quintela A, Garrido M, Gude F, Campos J, Linneberg A, Lojo S, Vidal C. Sensitization to cross-reactive carbohydrate determinants in relation to alcohol consumption. Clin Exp Allergy. 2008;38:152-60.

9. Carballo I, Alvela L, Pérez LF, Gude F, Vidal C, Alonso M, Sopeña $B$, Gonzalez-Quintela A. Serum concentrations of lgG4 in the Spanish adult population: relationship with age, gender, and atopy. PLoS One. 2016;11:e0149330.

10. Bousquet J, Menardo JM, Aznar R, Robinet-Levy, M, Michel FB. Clinical and immunologic survey in beekeepers in relation to their sensitization. J Allergy Clin Immunol. 1984;73:332-40.

- Manuscript received November 8, 2016; accepted for publication January 12, 2017.

Arturo Gonzalez-Quintela

Department of Internal Medicine Hospital Clínico Universitario 15706 Santiago de Compostela, Spain E-mail: arturo.gonzalez.quintela@usc.es 


\section{Eosinophilic Cellulitis Possibly Due to Mosquito Bite With High IL-5 Production}

Mashima E, Sawada Y, Yamaguchi T, Ohmori S, Haruyama S, Yoshioka M, Okada E, Nakamura M

Department of Dermatology, University of Occupational and Environmental Health, Kitakyushu, Japan

J Investig Allergol Clin Immunol 2017; Vol. 27(2): 149-150 doi: 10.18176/jiaci.0142

Key words: Eosinophilic cellulitis. IL-5. Mosquito bite.

Palabras clave: Celulitis eosinofílica. IL-5. Picadura de mosquito.

Eosinophilic cellulitis is a rare hypereosinophilic disease [1] that has been described in association with mosquito bites and drug hypersensitivity [2-4]. In some patients with eosinophilic cellulitis, peripheral blood mononuclear cells (PBMCs) exhibit a strong response to mosquito salivary gland (MSG) extract. However, it remains unclear whether MSGstimulated PBMCs promote IL-5 production, which is one of the main pathogenetic factors in patients with eosinophilic cellulitis [5]. Herein, we report a case of eosinophilic cellulitis with a strong response to MSG extract and analyze IL-5 production by PBMCs under MSG stimulation.

A 90-year-old man noticed erythematous papules on his left lower leg after a mosquito bite and subsequently developed edema in the affected area. At first he was diagnosed with cellulitis and administered cefotiam in a nearby dermatology clinic. However, the eruption proved to be intractable. Laboratory examination revealed elevated white blood cells with eosinophilia $(5693 / \mu \mathrm{L})$. After topical application of betamethasone butyrate propionate ointment, the skin eruption gradually improved. Two months later, the patient was bitten again by a mosquito on both legs, resulting in the gradual development of erythema and edema. He was referred to our department for evaluation. Physical examination revealed palpable annular erythema and edema on both legs (Figure A, B). A skin biopsy taken from the site of the erythematous eruption showed an eosinophil-rich infiltration in the dermis (Figure C, D). The blood tests again showed eosinophilia $(528 / \mu \mathrm{L})$. Since a typical flame figure was not observed, we diagnosed the skin eruption as eosinophilic cellulitis, possibly in an early stage. Computed tomography ruled out the presence of internal malignancy. After the administration of oral prednisolone $15 \mathrm{mg}$ per day, his skin eruption improved gradually over the course of 1 month.

Although hypersensitivity to MSG has been reported in patients with eosinophilic cellulitis, it remains unclear whether MSG extract stimulates IL-5 production by PBMCs. To clarify this issue, we performed a lymphocyte stimulation test (LST) with MSG extracts using PBMCs from this patient, as described previously $[2,6]$. The MSG extracts were prepared from 2 endemic species Aedes albopictus and Culex pipiens pallens. These extracts induced a high proliferative response in

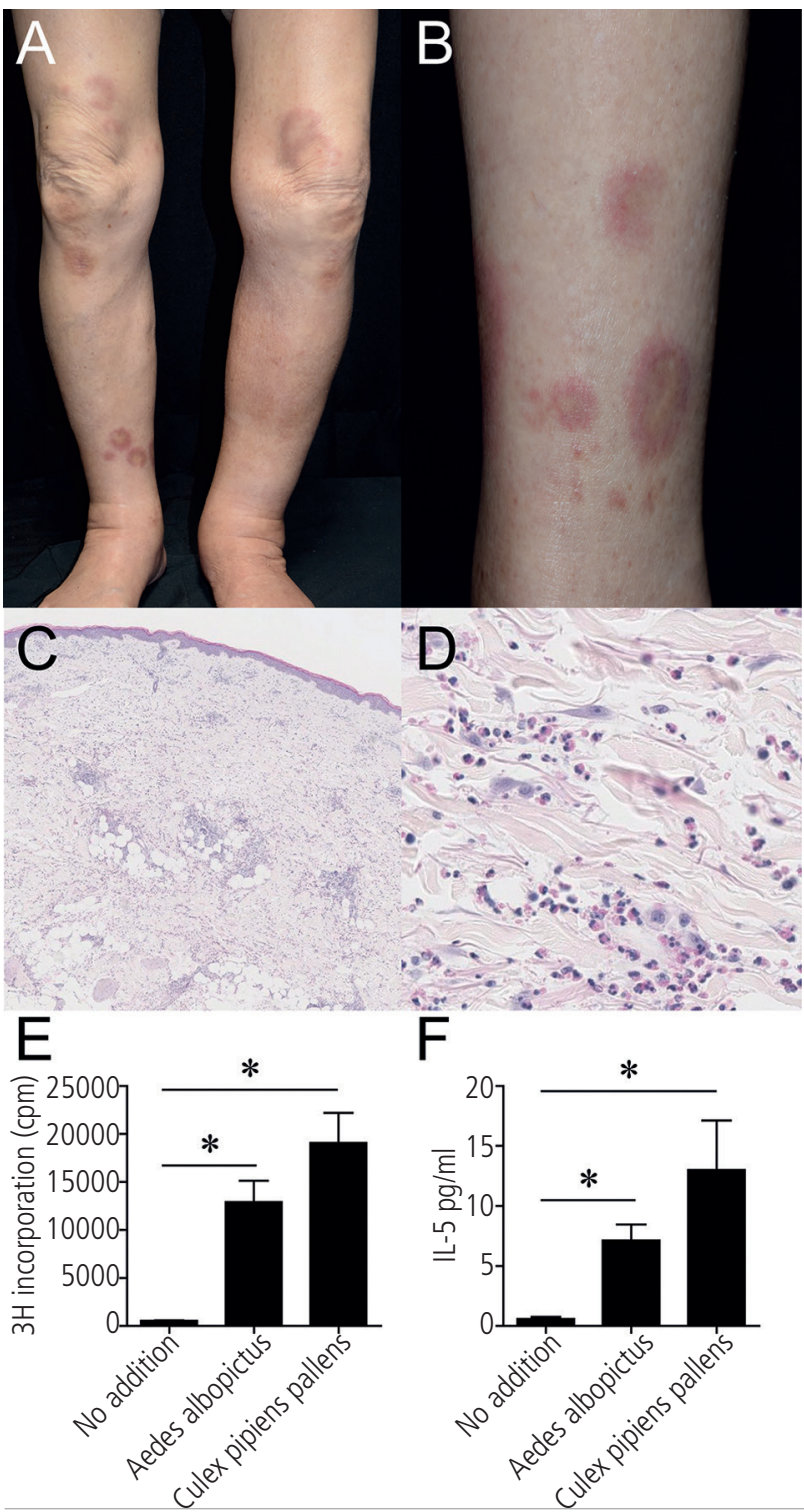

Figure. A, Edema and sporadic annular erythema on the patient's thigh and lower leg (low-magnification view). B, Elevated annular erythema scattered on the patient's lower left leg. C, Inflammatory cells infiltrated in the dermis (low-magnification view). D, Eosinophil-rich infiltration in collagen fiber gap regions in the dermis (high-magnification view). $E_{\text {, }}$ PBMC response to MSG extracts. PBMCs were cultured for 72 hours with the indicated MSG extracts. The proliferative responses were assessed by $3 \mathrm{H}$-thymidine incorporation (cpm). F, IL-5 concentration in culture supernatant in (E). ${ }^{*} P>.05$ (t test). MSG indicates mosquito salivary gland; PBMC, peripheral blood mononuclear cells.

the PBMCs (Figure E). Therefore, we diagnosed the patient's skin eruption as a possible high proliferative response of PBMCs to MSG extracts. Next, to analyze IL-5 production by MSG extract-stimulated PBMCs, the concentration of IL-5 in the supernatants of MSG-stimulated lymphocyte cultures was measured by ELISA and found to be significantly increased under stimulation of MSG by A albopictus and Culex pipiens pallens (Figure F). Both extracts showed positive reactions in the LST, while PBMCs from a healthy individual showed no 
significant IL-5 production under the same conditions. These results indicate that MSG might exacerbate IL-5 production by PBMCs and subsequently exacerbate eosinophil activation in patients with eosinophilic cellulitis. Because eosinophilic cellulitis is a relatively rare entity, further investigation is needed to clarify its pathogenesis.

\section{Acknowledgments}

We thank Professor Hiroyuki Matsuoka (Division of Medical Zoology, Department of Infection and Immunity, Jichi Medical University) for preparing the mosquito salivary gland extract.

\section{Funding}

The authors declare that no funding was received for the present study.

\section{Conflicts of Interest}

The authors declare that they have no conflicts of interest.

\section{References}

1. Wells GC. Recurrent granulomatous dermatitis with eosinophilia. Trans St Johns Hosp Dermatol Soc. 1971;57(1):46-56.

2. Koga C, Sugita K, Kabashima K, Matsuoka H, Nakamura $M$, Tokura Y. High responses of peripheral lymphocytes to mosquito salivary gland extracts in patients with Wells syndrome. J Am Acad Dermatol. 2010;63(1):160-1.
3. Kambayashi $Y$, Fujimura $T$, Ishibashi $M$, Haga $T$, Aiba $S$. Eosinophilic cellulitis induced by subcutaneous administration of interferon-beta. Acta Derm Venereol. 2013;93(6):755-6.

4. Tatsuno K, Fujiyama $T$, Matsuoka $H$, Shimauchi $T$, Ito $T$, Tokura Y. Clinical categories of exaggerated skin reactions to mosquito bites and their pathophysiology. J Dermatol Sci. 2016;82(3):145-52.

5. Yagi H, Tokura Y, Matsushita K, Hanaoka K, Furukawa F, Takigawa M. Wells' syndrome: a pathogenic role for circulating CD4+CD7- T cells expressing interleukin-5 mRNA. Br J Dermatol. 1997;136(6):918-23.

6. Mashima E, Sawada $Y$, Ohmori S, Omoto D, Haruyama S, Yoshioka M, Nishio D, Nakamura M. Annular erythematous eruption with a high response to mosquito bite. J Dermatol. 2016;43(11):1378-80.

- Manuscript received December 5, 2016; accepted for publication, January 17, 2017.

Yu Sawada

Department of Dermatology

University of Occupational and Environmental Health

1-1 Iseigaoka, Yahatanishi-ku

Kitakyushu 807-8555, Japan

E-mail: long-ago@med.uoeh-u.ac.jp 